\title{
Perceived social support systems during athletic injury recovery in collegiate club sport athletes
}

Jacqueline A. Loutsch

West Virginia University

Follow this and additional works at: https://researchrepository.wvu.edu/etd

\section{Recommended Citation}

Loutsch, Jacqueline A., "Perceived social support systems during athletic injury recovery in collegiate club sport athletes" (2007). Graduate Theses, Dissertations, and Problem Reports. 2521.

https://researchrepository.wvu.edu/etd/2521

This Thesis is protected by copyright and/or related rights. It has been brought to you by the The Research Repository @ WVU with permission from the rights-holder(s). You are free to use this Thesis in any way that is permitted by the copyright and related rights legislation that applies to your use. For other uses you must obtain permission from the rights-holder(s) directly, unless additional rights are indicated by a Creative Commons license in the record and/ or on the work itself. This Thesis has been accepted for inclusion in WVU Graduate Theses, Dissertations, and Problem Reports collection by an authorized administrator of The Research Repository @ WVU. For more information, please contact researchrepository@mail.wvu.edu. 
Perceived Social Support Systems During Athletic Injury Recovery in Collegiate Club Sport Athletes

\author{
Jacqueline A. Loutsch
}

Thesis submitted to

School of Physical Education

at West Virginia University in

partial fulfillment of the requirements

for the degree of

\author{
Master of Science \\ in \\ Athletic Training \\ Michelle A. Sandrey, PhD, ATC, Chair \\ Sam Zizzi, EdD \\ Kristen Dieffenbach, $\mathrm{PhD}$
}

School of Physical Education

Morgantown, WV

2007

Keywords: club sport athletes, social support system, athletic injury 


\begin{abstract}
Perceived Social Support Systems During Athletic Injury Recovery in Collegiate Club Sport Athletes.
\end{abstract}

Jacqueline A. Loutsch

Context: Social support systems can be a key aspect in the overall health of the athlete, both physically and psychologically. It is important to be aware if an athlete is receiving the appropriate social support to aid them through their career. Objective: The purpose of this study is to determine which types of social support systems are used and who provides the different types of support. A secondary purpose is to investigate the types of social support that are perceived to be most important. Design: A prospective descriptive analysis about the influence of social support systems after an athlete is injured within club sports was used. The information was gathered by individual questionnaires as well as a face to face interview. Setting: A NCAA Division I institution in north central West Virginia. Participants and Other Patients: There were a total of 7 participants, both male and female, that completed the questionnaire and the interview. Seventy one and four tenths percent of the participants played rugby $(\mathrm{n}=5)$, while the remaining participants played ice hockey $(\mathrm{n}=2)$. The mean age was $21.29 \pm$ 1.38 Interventions: A 10-item demographic questionnaire and a social support questionnaire on the types of support provided were distributed to the club sport athletes at West Virginia University. There was also a 15 minute interview consisting of 10 questions that each athlete completed. Main Outcomes Measures: Coaches and certified athletic trainers will play an important role in the social support system in collegiate club sport athletes. Listening support, emotional support, reality conformation, and personal assistance will be ranked as most important to the club sport athletes. Athletic trainers will play an important role in providing listening support, coaches will be important providers of task challenge and task appreciation, and teammates will be important providers of reality conformation and emotional support. Results: The results of this study show that these club sport athletes are overall satisfied with the social support that they have received during injury rehabilitation. Athletic trainers were identified to have provided the most listening support in both the questionnaire (mean rank $=1.57,71.4 \%$, $\mathrm{n}=5$ ) and the interview. Coaches were also reported to have provided task appreciation (mean rank=1.71, 51.7\%, $\mathrm{n}=4$ ) and task challenge (mean rank=1.29, 71.4\%, $\mathrm{n}=5$ ) Athletic trainers were also the most common reported provider of overall social support in both the interview and the questionnaire $(71.4 \%, \mathrm{n}=5)$. Other common providers of social support mentioned by these athletes were family, teammates/friends, and coaches. The results from the questionnaire did not find any type of social support that was reported as most important. Conclusion: Collegiate club sport athletes are aware and satisfied with the support that they received during injury rehabilitation. These athletes reported how important their athletic trainer's role was in injury rehabilitation. Most club sports do not have an athletic trainer as members of their social support network. This study indicates how important an athletic trainer can be to injured collegiate club sport athletes. These athletes reported that the only aspects of social support that they would have wanted more of is financial assistance and to spend more time on rehabilitation. 


\section{ACKNOWLEDGEMENTS}

First I would like to thank Dr. Sandrey for all of her time and effort that she put towards myself and my research. You have helped me with everything from finding sources to just being there for me as a sounding board for ideas. Thank you so much for all of your help.

I would also like to thank the other members of my committee, Dr. Sam Zizzi and Dr. Kristen Dieffenbach. Thank you for pushing me to get the best out of my research, you always had my best interest in mind. Thank you for all of the input you have given me on my thesis.

I would like to say thank you to all of the club sport athletes who had volunteered to participate in my research. Thank you for making this possible for me.

To my parents and family I want to send a big thank you for providing me with unending love and support. You believed in me even when I didn't believe in myself. I could not have gotten through it without you!

A big thank you also needs to go out to all of my friends. You were always there to talk and I could not have done it without all of you!

I would also like to say thank you to my colleague, Brian Angelotti. Thank you for putting up with me on all of my stressful days. I wish you the best of luck next year with club sports and intramurals.

Finally, I would like to thank everyone at HealthWorks Rehab and Fitness who have been a part of my time here in West Virginia. Thank you for all of your support and your constant interest in me and my education. 


\section{TABLE OF CONTENTS}

ACKNOWLEDGEMENTS..........................................................ii

LIST OF TABLES.................................................................

LIST OF FIGURES.......................................................vii

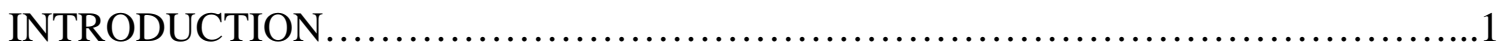

METHODS.....................................................................

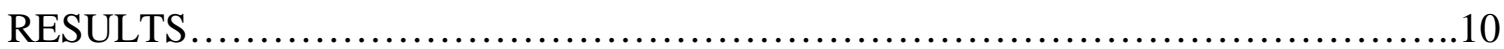

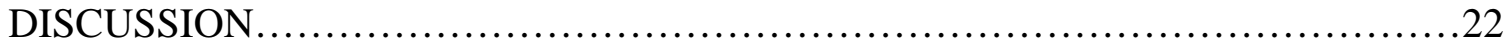

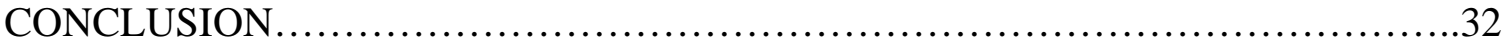

REFERENCES ..............................................................

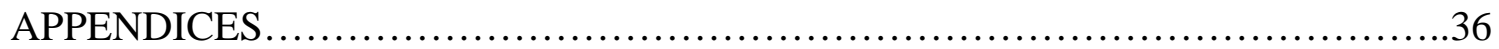

APPENDIX A. THE PROBLEM............................................37

APPENDIX B. LITERATURE REVIEW ...............................44

APPENDIX C. ADDITIONAL METHODS..................................78

APPENDIX D. ADDITIONAL RESULTS ..............................91

APPENDIX E. RECOMMENDATIONS FOR FUTURE RESEARCH........115

ADDITIONAL REFERENCES................................................116 
C1. Demographic Questionnaire............................................78

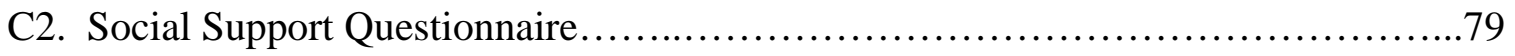

C3. Interview Questions.................................................... 84

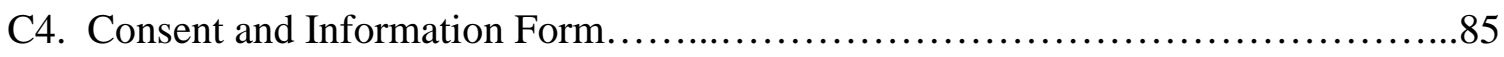

C5. Protected Health Information Form .......................................88

C6. Cover Letter............................................................90

D1. Demographic Information...........................................91

D2. Frequencies for Year in School.........................................92

D3. Frequencies for Gender..............................................92

D4. Frequencies for When Injury Occurred...................................92

D5. Frequency of Responses to Satisfaction with the Quality of Support...............93

D6. Frequency of Responses to Difficulty Obtaining More Support....................93

D7. Frequency of Responses to Having One or More Individuals Provide Support.....94

D8. Satisfaction With the Quality of Support by Sport...........................95

D9. Satisfaction With the Quality of Support by Gender..........................96

D10. Difficulty Obtaining More Support by Sport..............................97

D11. Difficulty Obtaining More Support by Gender..............................98

D12. Importance of Having One or More Individuals Provide Support by Sport........99

D13. Importance of Having One or More Individuals Provide Support by Gender......100

D14. Responses to Ranking of Those Who Provide Listening Support................101

D15. Responses to Ranking of Those Who Provide Emotional Support................102

D16. Responses to Ranking of Those Who Provide Emotional Challenge.............103 
D17. Responses to Ranking of Those Who Provide Reality Conformation...............104

D18. Responses to Ranking of Those Who Provide Task Appreciation................105

D19. Responses to Ranking of Those Who Provide Task Challenge..................106

D20. Responses to Ranking of Those Who Provide Tangible Assistance..............107

D21. Responses to Ranking of Those Who Provide Personal Assistance...............108

D22. Average Responses to Those Who Provided Each Type of Support..............109

D23. Responses to Ranking the Types of Support.............................110

D24. Average Responses to Ranking for the Types of Social Support.................111

D25. Most Important People Providing Social Support Throughout Injury Process....112 


\section{LIST OF FIGURES}

Figure

Page

D1. Interview Flow Chart....................................................113 


\section{INTRODUCTION}

Athletes, no matter what level or sport, have the potential to sustain an injury. How they manage their emotions and temporary disabilities greatly affect their injury process and outcome. An athletic trainer's first concern with an injury is often focused on the physical aspect of the rehabilitation process. With all the focus here, the athlete's psychological aspects of progression through the rehabilitation process are often unnoticed.

Injury is something that affects many athletes. As many as 17 million sport injuries occur each year among American athletes. ${ }^{1}$ It has also been shown that as many as eight out of 10 athletes are injured at some point during their high school and college careers. ${ }^{1}$ Injuries have the possibility to threaten the athlete's self-concept, belief system, social functioning, values, commitments, and emotional equilibrium. ${ }^{2}$ An athletes understanding of the different levels of stress as well as the causes is very important. ${ }^{3}$ The stress that results from an injury demonstrates the importance for athletes to be able to cope properly and utilize their social support systems.

Stress to an athlete can threaten and alter the ideal world in which they strive to create. In general this world leaves them feeling protected, comfortable, loved, and esteemed. ${ }^{2}$ Some common expected stressors of collegiate athletes pertain to injuries, academic hardships, forming peer relationships, and facing financial constraints. ${ }^{4}$ Any of these stressful experiences lead the athlete to perceive that the situational demands exceed their ability to cope with them. The inability to cope properly with persistent stress in sport may lead to decreased motivation, emotional distress, poor athletic performance, and eventual psychological burnout and withdrawal from competitive 
sport. ${ }^{5,6,7}$ Athletes experiencing burnout feel physically and psychologically exhausted from the demand of training and competing, perceive reduced sense of accomplishment, and experience sport devaluation in which they stop caring about sport and their performance. ${ }^{8}$ In any stressful situation proper coping can help the athlete change their original assessment and alter the way in which they deal with that stress. Stress can have the ability to alter injury recovery, especially when it is not recognized and confronted.

To cope successfully in sport an athlete must learn to regain their composure, establish a proper mental state, and maintain optimal arousal and concentration. ${ }^{2}$ Coping skills comprise behaviors and social networks that aid the athlete in dealing with problems, joys, disappointments, and stresses of life. ${ }^{8}$ Proper coping strategies help an athlete defend against negative life experiences which can lead to increased resiliency against injury and better adherence to rehabilitation if an injury were to occur. In general, coping is seen as a conscious effort to deal with stressful demands that consists of learned behavioral responses and lowers stress by limiting the importance of a dangerous or unpleasant conditions. ${ }^{1}$ How an athlete copes with certain stressors is based on how they individually perceive that situation.

Any injury that excludes an athlete from involvement in sport can be cognitively, emotionally, and behaviorally challenging. ${ }^{2}$ The occurrence of an injury may disrupt an athlete's focus and lead to emotional and psychological reactions, which are typically negative. In addition to the physical losses from an injury, there is also a decrease in physical conditioning and changes in lifestyle experienced from the lack of sport participation. Most athletes feel panic and helplessness when injured and their selfconcept and self-esteem, among other things, may be threatened. ${ }^{1,2}$ 
Social support may give the athlete a sense of identity and belonging, increase self-esteem, and perceived control in certain situations. ${ }^{9}$ Social support has repeatedly been found to be an important tool for enhancing a patient's recovery from injury. Social support involves a network of personal ties that serve to meet the need of the individual by reducing uncertainty during times of stress, providing companionship, and aiding in mental and physical recovery. ${ }^{10,11}$ The presence of an appropriate social support system is positively related to improved recovery in rehabilitation and decreased stress. ${ }^{12}$ Social support systems usually include teammates, coaches, team physicians, athletic trainers, sport psychologist, family, and friends. ${ }^{1,10,11}$ Social support systems provide information to athletes that they are loved and cared for, esteemed and valued, and part of a network of communication and mutual obligations. ${ }^{12}$

The social support system can provide eight different identified types of social support. These eight are listening support, emotional support, emotional challenge, reality conformation, task appreciation, task challenge, tangible assistance, and personal assistance. ${ }^{1,11,12,13}$ Social support is not only important to enhance injury rehabilitation, but overall athletic experience as well. It is important for athletes to realize that they are not alone during an injury and that they can rely on their social support system to help them deal with certain demands that may be out of their control.

A study by Bone and Fry ${ }^{11}$ with Division 1 athletes found that listening support was reported as the most important type of social support. They also reported that athletes indicated that athletic trainers played an important role in their social support network by providing technical challenge and tangible assistance. Technical challenge was related to developing rehabilitation exercises while pushing them to improve and 
tangible assistance was related to providing braces or taping and setting up doctor appointments. These athletes reported that it was easier to adhere to rehabilitation when their athletic trainer demonstrated alliance and confirmed their progress.

Rosenfeld et.al ${ }^{10}$ conducted research on social support with 170 Division 1 athletes and found that the coaches were described as providing technical challenge primarily and technical appreciation secondarily. The coaches in this study were not listed as providing any listening support, emotional support, or shared reality conformation. The teammates provided technical challenge primarily and listening and shared reality secondarily. Their friends were described as providing listening and shared reality primarily and emotional support secondarily. The athlete's parents provided technical appreciation and emotional support primarily and listening support secondarily. Robbins and Rosenfeld ${ }^{1}$ also researched social support using 35 D1 athletes and found that these athletes reported that they more satisfied with the support they received from their athletic trainers than from their coaches. The athletes perceived that the athletic trainers listening support, task appreciation, task challenge, and emotional challenge are more influential to their well-being than support from their coaches. All of these athletes also mentioned that more support from their coaches would be accepted and appreciated.

Most research conducted on the social support following injury used collegiate or elite athletes. There is little research performed using collegiate athletes that participate in club sports verses NCAA approved sport teams. Club sport athletes are enrolled students at the university who participate in a sport that is not recognized by the NCAA. These athletes are unable to receive scholarships for their participation or any expenses to 
play. Club sports do have organized competitions with other club sport teams outside of their university. Club sports are organized and administered by students and each club has an advisor to provide guidance. Club sport teams report to the Office of Campus Recreation and each team must be registered with Student Organization Services. Therefore, club sport athletes may have alternate reasons for participation compared to NCAA Division 1 athletes. Along with different reasons for participation, there may be alternate social support systems as well as coping strategies for similar injuries. Therefore, the purpose of this study is to determine which types of social support systems are used and who provides the different types of support. A secondary purpose is to investigate the types of social support that are perceived to be most important to club sport athletes.

\section{METHODS}

The design was a prospective descriptive study which recognized the influence of social support systems after an athlete was injured within club sports. The information provided was gathered by individual questionnaires and interviews that were given to each athlete. The dependent variables were the types of support: listening support, emotional support, emotional challenge, reality conformation, task appreciation, task challenge, tangible assistance, and personal assistance.

Participants

The participants were chosen by convenience sampling. There were seven participants that were club sport athletes from a major Midatlantic university with an average age of $21.29 \pm 1.38$ years. The club sports that were included were men’s and women's rugby ( $\mathrm{n}=5)$ as well as men's ice hockey $(\mathrm{n}=2)$. The participants were both 
male $(n=4)$ and female $(n=3)$. All participation was voluntary and was dependent on their current injury. Each participant sustained an injury that required them to be out of participation for at least two weeks. The study was approved by the Office of Research Compliance at West Virginia University.

Instruments

A demographic questionnaire was used to gather additional information (Table C1). The questions were designed to identify how long the athlete expected to be out of participation with their injury, the type of injury that they sustained, when the injury occurred, and the athlete's position and starting status on the team at the time of injury. The questionnaire was reviewed by certified athletic trainers for clarity and readability and by a psychometric expert for face and content validity.

The next instrument used was a questionnaire (Table C2) based on the Social Support Survey-Clinical Form (SSS-C) developed by Richman et al. ${ }^{14}$ and later used by Henert. ${ }^{15}$ Modifications were made by Kestner ${ }^{16}$ for the purpose of her research and those changes to the questionnaires were used for this study. The changes were minor and included removing the first question that asked to list specific individuals who provided that type of support and in place of that was a list of people that the participants were to rank in order of importance for each type of support. An additional section was added at the end of the questionnaire that allowed the participant to rank the types of social support in order of importance. The questionnaire examined the types of social support each athlete perceived they obtain and who provided the support, it was administered to the athlete during their first week of rehabilitation. 
Structural validity, construct validity, and reliability of the SSS-C were tested by Richman et al. ${ }^{14}$ Structural validity was assessed through correlation matrices across the four questions and across the eight types of support. Results showed that the four questions asked for each type of support measured distinct aspects of each type of support. He also found that the number of support providers remained stable across the eight types of support. Richman thus concluded that the content of the SSS-C is more inclusive than other measure of social support. In order to test construct validity 28 undergraduate students completed the survey and the results of analysis supported the construct validity of SSS-C. Reliability was tested by having 27 individuals complete the survey twice, most at a two week interval and the remaining five completed it at a five week interval. Item by item correlations were then calculated and the results revealed that all but four of the 32 correlations, between the first and the second time testing, were statistically different. Significant correlations ranged from a low of .44 $(\mathrm{p}<.01)$ for task challenge importance and task appreciation for satisfaction, to a high of .87 ( $\mathrm{p}<.001)$ for tangible assistance satisfaction. Mean correlations for the 28 significant findings was .60, with four of them at .8 and above, eleven of them .65 and above, and seven of them were below .5. These results show that the subscales of the SSS-C are reliable measures of the multidimensional construct of social support.

The last instrument used was a set of interview questions that was based on the social support questionnaire (Table C3). Ten interview questions were used to provide more in depth views on the athlete's perceived social support systems during rehabilitation for their injury. The questions were developed based on the purpose of this study. The interview started by asking the athlete to talk about their experience coping 
with their injury. The next questions were guided at finding what was difficult or challenging during rehabilitation. The athletes then talked about their satisfaction with social support and who they perceive are their top three providers of social support. Then they were asked about their rehabilitation experience and what could have helped then cope. The interviews ended by having the participants talk about their specific experiences with certain types of social support. The interview questions were reviewed by certified athletic trainers for clarity and by a psychometric expert for face and content validity.

Procedures

The athletes were approached during the first week of rehabilitation following an injury to participate in the study. This injury was classified by a certified athletic trainer as one likely to keep the athlete out of participation for at least two weeks. Prior to completing the questionnaire, the athletes filled out an informed consent form (Table C4) as well as a Protected Health Information (PHI) form (Table C5). The Protected Health Information form allowed any medical records pertaining to the injury to be used during this study. Once the consent was given, the athlete filled out a demographic questionnaire as well as a social support questionnaire. A code was placed on all questionnaires so that anonymity was assured and for the purpose of identifying the subject number. The demographic questionnaire provided additional information about the athlete and their injury. The directions for completing the questionnaire as well as the purpose of the study was addressed and explained in a cover letter (Table C6) which the athletes read before completion. To reduce bias of responses, both of the demographic questionnaire as well as the social support questionnaire were given to the athletes by the 
investigator before leaving the room so as to allow the athletes to complete the questionnaires on their own. Once the questionnaires were completed the athletes placed them in a provided envelope and returned them to the investigator.

After questionnaire completion the athlete scheduled a time with the investigator for their recorded interview on their perceived social support systems during the second week of their rehabilitation. The interviews (Table C3) were conducted by an athletic training graduate student during the second year of her master's degree program. The interviewer was trained by reading several qualitative research articles and thesis dissertations. The interviewer also conducted pilot interviews on other club sport athletes as well as other athletic trainers. Feedback was received by the participants in the pilot interviews. All interviews took place in a private room at HealthWorks Rehabilitation and Fitness and ranged from 11:15 minutes to 15:23 minutes. The average length of the interviews was 13:55 minutes. The interviews were audio taped. Each session started by stating the subject code before the interview began. The codes from the questionnaires were used for the purpose of matching the subject with their interview. Once the interview was complete no additional information was needed from the athlete. Data Analysis

For the purpose of data analysis, the questions from the social support survey were used multiple times for each type of support. The percentage of responses to the questions was described by type of support, sport, and gender. Responses to questions 13 were examined by their trends. Question 4, which involved ranking, as well as ranking the types of social support, was examined using descriptive statistics and means for comparisons. 
During data collection the tape from the interviews were transcribed verbatim to a separate word documents. Once transcribed, the scripts were read and re-read to search for raw data responses among the participants that could be identified and related. The common data responses (quotes or paraphrases) were then organized into patterns of like responses to be placed in one of three groupings. Related comments were placed in one of three headed columns as common themes: coping with the injury, social support systems, and types of social support.

\section{RESULTS}

Demographic Questionnaire

The athletes were asked to complete a demographic questionnaire before taking the social support survey. A total of seven participants completed the demographic questionnaire. The average age of the participants was $21.29 \pm 1.38$ years. The participants were both male $(n=4)$ and female $(n-=3)$ and participated in either rugby or ice hockey, as $71.48 \%$ of the participants played rugby $(n=5)$, while the remaining $28.6 \%$ participants played ice hockey $(n=2)$. Five of the subjects that participated were starters when their injury occurred and the remaining two participants were substitutes. The year in school ranged from freshman to senior, as $28.6 \%(n=2)$ were seniors, $42.9 \%(n=3)$ were juniors, $14.3 \%(n=1)$ were sophomores, and $14.3 \%(n=1)$ were freshman. None of the injuries sustained by these participants required surgery and only one of them were season ending. Two of the subjects sustained acromioclavicular (AC) sprains, two had ACL sprains, and the other injuries were shin splints, displaced teeth, and patella-femoral pain syndrome. The time out of sport participation from injury ranged from two to eight weeks. All of the injuries occurred in the spring semester, with $57.1 \%(n=4)$ during a 
game and the remaining $42.9 \%(n=3)$ occuring at practice. The responses to the demographic questionnaire are listed in Table D1. Frequencies for gender, year in school, and when the injury occurred are listed in Tables D2-4.

Social Support Questionnaire

The first three questions under each type of support asked the participants to rate their satisfaction with that type of support, difficulty of obtaining more of that type of support, and importance of having one or more people provide that type of support on a Likert scale from 1-5. The results illustrated that only one of the participants expressed dissatisfaction with the quality of support received. That dissatisfaction was indicated to be with task appreciation. All of the other types of support indicated no dissatisfaction. The results showed that the participants were overall satisfied with seven out of the eight types of social support listed. The participants were either satisfied or very satisfied with all types of the social support except tangible assistance. Satisfaction ranged from satisfied for Listening support (14.3\%, n=1), Emotional support (28.6\%, n=2), Emotional challenge (57.1\%, $\mathrm{n}=4)$, Reality conformation $(57.1 \%, \mathrm{n}=4$,) Task appreciation $(57.1 \%$, $\mathrm{n}=4)$, Task challenge (42.8\%, $\mathrm{n}=3$ ), Tangible assistance $(28.6 \%, \mathrm{n}=2)$, and Personal assistance $(42.8 \%, n=2)$ to very satisfied for Listening support $(85.7 \%, n=6)$, Emotional support $(71.4 \%, n=5)$, Emotional challenge $(28.6 \%, n=2)$, Reality conformation (14.3\%, $\mathrm{n}=1)$, Task appreciation $(14.3 \%, \mathrm{n}=1)$, Task challenge $(28.6 \%, \mathrm{n}=2)$, Tangible assistance (28.6\%, $\mathrm{n}=2)$, and Personal assistance $(28.6 \%, \mathrm{n}=2)$. Frequencies can be found in Table D5.

Responses to difficulty obtaining more support showed that the majority of the participants indicated that it was easy or very easy to obtain. The responses to easy and 
very easy were Listening support (85.7\%, n=6), Emotional support (85.7\%, n=6), Emotional challenge (85.7\%, n=6), Reality conformation $(71.4 \%, n=5)$, Task appreciation $(71.4 \%, n=5)$, Task challenge $(85.7 \%, n=6)$, Tangible assistance $(57.1 \%$, $\mathrm{n}=4)$, and Personal assistance $(85.7 \%, \mathrm{n}=6)$. These frequencies can be found in Table D6.

The responses for the importance of having one or more individual providing support show a wide variety of responses ranging from not important to very important. The majority of the responses indicated that they were indifferent or just important. The responses for indifferent ranged from a low of $14.1 \%(n=1)$ for emotional challenge to a high of $57.1 \%(n=4)$ for task appreciation and task challenge. The responses for important ranged from a low of $14.1 \%(n=1)$ for reality conformation and tangible assistance to a high of $57.1 \%(n=4)$ for listening support, emotional support, and emotional challenge. Frequencies can be found in Table D7.

Percentages of responses for all three questions were also compared by sport and by gender. These results can be found in Tables D8-13. There was no difference in responses to the satisfaction of support received when compared by sport or gender. The responses were also similar for the questions pertaining to difficulty obtaining more support and importance of having one or more individuals providing support.

The subjects were also asked to rank athletic trainer/physician, coach, teammates, family, friend, and other from 1-6 (1=provided the most support, 6=provided the least support) according to who provides them with social support. This ranking was completed for all eight types of social support. The responses are listed in Table D14-21. 
Averages for ranking of the individuals were also calculated for each group providing the support. According to the averages, athletic trainers were ranked as the group of individuals to have provided the most listening support (mean=1.57, 71.4\%, $\mathrm{n}=5$ ) and family was indicated to have provided the most emotional support (mean=1.86, $57.1 \%, \mathrm{n}=4$ ) and tangible assistance (mean $=1.29,85.7 \%, \mathrm{n}=6$ ). Coaches were perceived to have provided the most task appreciation (mean $=1.71,57.1 \%, \mathrm{n}=4$ ) and task challenge (mean=1.29, 71.4\%, $\mathrm{n}=5$ ). The participants teammates were not indicated in the questionnaire to have been important providers of any specific type of social support. These results can be found in Table D22.

The last part of the survey asked the participants to rank the types of social support from most important (1) to least important (8). The results represented a wide variety of responses. The average rank for the types of support ranged from task challenge (2.75) to the least important for tangible assistance (5.5). The responses are listed in Table D23 and the averages are listed in Table D24. Participants were also asked to list the two most important groups of individuals to provide social support. Athletic trainer was the most often listed by these participants $(71.4 \%, n=5)$. Other groups of individuals listed were family $(42.8 \%, \mathrm{n}=3)$, friends/teammates $(42.8 \%, \mathrm{n}=3)$, and coaches $(42.8 \%, \mathrm{n}=3)$. The responses are listed in Table D25. Interview Questions

Coping with an injury: The majority of the participants, when talking about how to cope with an injury, stated the hardest part for them was not being able to contribute to their team like they were used to doing. Six of the participants reported that it was "hard to watch the team play and practice”. The subjects reported that they were more 
concerned about how the team would deal without them than they were with their concern about the injury. One of the participants described having to cope with an injury this way,

Well first of all it was tough to cope with because I obviously couldn't play. I am used to practicing and playing with the team every day. It was really hard to sit back and not be able to play, especially since it was at the end of our season and I know I could have been helping the team out.

Three of the participants also stated that another difficult aspect to cope with was the type of injury they sustained. One of the athletes said "Well it was difficult at first especially not knowing what the injury was. They thought it was a more serious injury at first but, that was probably the most difficult part.” Another participant stated it was difficult to cope because the injury stems from body type and that "its just been frustrating just for the fact that, um, we had to take different steps to try and fix it.”

When asked what has been different or challenging, five of the participants reported that some type of daily living had been altered which made it hard for them. The participants with lower extremity injuries stated that initially just walking around was a challenge as well as having to use stairs and walking up and down hills to go to class. Four of them also reported that getting a good night sleep was difficult to obtain, either because of the location of their injury or just pain in general. One athlete put it this way "It was a hard thing to adjust too. At first it was uncomfortable just to talk and be able to sleep.” Six of these athletes mentioned that they have not been sidelined from an injury before so it was challenging to add the additional time for rehabilitation. One of the athletes summed it up by saying,

The whole process was kind of challenging. Um, having to watch and not be a part of everything was probably the most difficult thing. But um putting hours into doing the rehab and uh not knowing what is going to come out of it was also 
difficult. They decided that they weren't going to do surgery so not knowing how long or what it was going to take was challenging.

The participants were also asked how others have helped them cope with their injury. All of the athletes mentioned receiving help from a variety of different individuals including coaches, teammates, athletic trainers, and family. According to the athletes, most people helped them cope by just being there to listen and understand how they felt and what they are going through. The following athlete explains how the team and athletic trainer helped cope with being injured,

Just my teammates talking about their injuries. You know everybody has something that they have to deal with, it just makes me feel better about it. The trainers can always recognize when I am not dealing to well with it, they are really easy to talk to. Just everyone making me feel comfortable even though I can’t play is helpful.

All of the athletes found that it was helpful when their teammates would ask them how they were doing. The injured athletes stated that it helped them deal with their injury when they heard their teammates talking about how they have been injured before and what they went through.

Five of the athletes also stated that it was helpful to have athletic trainers at practice and games. One athlete reported "Well the trainer was at the game when I hurt my shoulder. They were able to tell me what happened and what I have to do for it next. It's nice to know that they are there for us when we get hurt.” Only a three of the athletes mentioned receiving help from their coaches. One of the athletes stated "My coaches staying along with it the whole time and staying on top of doctors reports and therapy reports and stuff was really helpful.”

Social support systems: Social support was defined to all of the participants during their interview to help familiarize themselves with the questions that were asked. 
They were told that social support is the presence of others whom you can rely on and know that they value and care for your well-being. According to the participants in this study, satisfaction with their social support was really high. Only one of the athletes stated that they were not fully satisfied with their social support. All of the other participants mentioned how helpful their teammates and athletic trainers were, and three of them mentioned their coaches. The interview reflected the satisfaction from the questionnaire as the injured athletes were very satisfied with how accepting their teammates were to their injury. One athlete reported,

I was really pretty satisfied with the support I received. My friends kind of stuck by me during it and I didn't feel out-casted. At first I did feel like an outcast because I couldn't play but they did try you know to have me come in and still be a part of the team. Um, and everyone was really nice, they understood that I was going to come back and this injury was just a temporary thing.

The athlete's teammates were a big reason why they were very satisfied with social support received. Reality conformation was a common theme found when the participants talked about their team. Social support from a teammate was described by one athlete as "My teammates, they helped me out a lot because a couple of my teammates have been hurt before with the same injury. They have been there before and knew what I was going through so they always listened to me.” Having a team that was sympathetic and willing to put themselves in their position was very helpful to the athletes. Five of the participants also mentioned that they were satisfied with their social support because of the accessibility of their athletic trainer. One athlete mentioned "The trainers are also there at practice asking me how I'm feeling today and making sure that I am doing all of my home exercises and stretches.” These five athletes mentioned that it was really helpful to have the athletic trainer at practice and games for them. 
Participants were also asked to talk about the three people who they perceived to have provided them with the most social support during their injury rehabilitation. The people that were mentioned by the athletes were friends/teammates, family, athletic trainer, physician, coach, and girlfriend. All but one of the athletes stated that their athletic trainer was one of the top three to have provided them with support. One of the athletes described their importance by stating "Our trainers are also important because they are always asking how my shoulder is and I know they are there to help me get better." Friends and teammates were also mentioned by six of the seven athletes. Most of the participants stated that the majority of their friends are their teammates, so the two words can be used interchangeably. The importance of the team is described by one participant by stating "First of all I would say that it was my teammates because we are out there playing games together everyday and they just, they know that uh, it hurts to not be out there playing with them so they provide me with some support that I need.” Another common provider mentioned was their families as indicated by four atheltes. A few of the reasons that families are so important is because "they would always call to talk and check up on me”, "they are always willing to listen”, and because "they were always understanding and supported me.”

The participants were also asked about how their rehabilitation was going and what could have made it better or more successful. The two most common themes found had to do with finances and time constraints. One athlete had trouble getting an MRI because of her out of state insurance and stated if she could have seen a doctor right away "I would have been able to get an MRI and find out what was wrong right away instead of waiting around and not being able to do anything about it.” Other subjects stated that 
having money for braces, doctor's appointments, and orthotics would have helped a lot throughout their rehabilitation. Four of the subjects also found it hard to schedule time around their busy day for therapy. It was hard for the athletes to find time with class, practice, and their job to schedule rehabilitation time. One athlete stated,

Nothing could have made it gone that much smoother. I mean if I could have had more time to put into it just as regards to like school and stuff. I mean it was difficult to try and schedule around school and practice and stuff. I mean there was nothing really that could have made it that much better. Just not having the injury would have been nice!

Another athlete reported "Just having more time to put into it would have helped. I also have a job, plus practice and work so it was hard to find time. It was hard to get motivated to find time."

Four of the seven subjects stated that they did not need anything else to help them cope with their injury. One athletes stated "I don't think I really needed anything else. Everyone is really nice and accepting of me having to take two weeks off.” Another athlete said “I don't think I needed anything else. I am really satisfied with how it’s going. I accepted what happened and I am excited to get out there and play again.” The remaining three subjects reported that they could have used some more help in coping with their injury. One subject stated,

Well, being in college and being away from home and my parents, I couldn't really talk to them much, which I was used to doing. I called them on the phone and talked to them a couple times and they helped me through it a little bit but it would have been nice to see them but that's what happens when you go to college.

The other two subjects mentioned that more knowledge about their injury as well as understanding from others that their injury takes time would be helpful in coping with their injury. Most athletes do not know or talk about difficulty coping with an injury. 
These interviews indicate that athletes will always be willing to accept more support and aid in coping as well and more information about what kind of injury they are dealing with.

Types of social support: The last portion of the interview concentrated on asking the athletes to elaborate more on specific types of social support they may have received. All of the subjects felt that they received sufficient listening and emotional support during their injury rehabilitation. All but one of the subjects mentioned how their doctor or athletic trainer contributed by listening or showing emotional support. One athlete stated "Our trainer had to deal with my whiney self, she always was willing to listen and deal with me when I was injured." The other athletes described their support as "they listened to me complain”, "the trainer obviously listened when I talked about how I feel”, "they listened and understood what I was going through", and "the trainer saw me cry a lot and helped me deal with that.” Another common provider of listening and emotional support indicated by these athletes was their teammates. One common theme among teammate support was that they always listened to them complain about their injury and understood what they were going through. This type of support can more commonly be described as reality conformation, which is support given by people who are similar to them and help confirm their perceptions. One of the subjects summed up their support from both their teammates and the athletic trainer by stating,

Um, well I complained to the trainers a lot. Just about every day! Um, probably just from my friends on the team, like my closer friends on the team and they would hear about it everyday if it would hurt or not. I mainly got it from my teammates and the trainer being there just to listen to me and support me.

Only two of the subjects mentioned their coaches when talking about listening and emotional support. One of the subjects said "My coach also understands and isn't 
pushing me at all.” The other subject stated “Our coach isn’t really an emotional guy but I could tell that he was cool with it and understood. I know that I have support there even though he may not show it.”

The participants indicated that they felt they did not receive much tangible or financial assistance. The only thing they reported was that they still used their parents insurance to cover the doctor's bills. Only one of the subjects had a problem using her out of state insurance to cover her appointment. She said “Um, I didn’t receive any financial assistance cause I am from Philadelphia and my insurance couldn’t come over to here. It wouldn't even let me go to Pittsburgh to try and see a doctor and get an MRI or anything. So I had to wait until I could go home.” One of the subjects explained why they don’t receive any tangible assistance by stating “I really don’t get any financial assistance. My insurance did help cover my doctor's appointment. But being a club sport we get no money from the university, everything we have we have to pay for at the beginning of each season out of pocket.”

All of the personal assistance mentioned by the participants came from either their teammates or the athletic trainer. The athletes stated that their teammates were helpful by giving rides to doctor's appointments and to and from practices. The athletic trainers provided personal assistance by setting up doctor's appointments, providing ice, tapes, and wraps, and also by giving rides to doctor’s appointments.

The participants were also asked to talk about any task challenge or task appreciation they may have received during their injury rehabilitation. Five of the participants were challenged with activities of daily living. One of the participants with an upper extremity injury said "At first it was challenging to get dressed and do the daily 
things just because of the pain. But that doesn't bother me too much anymore. It's still kind of hard to sleep at night because sometimes I roll over on it.” The participants also mentioned that a lot of the challenge came from wanting to get back to practice as soon as possible. One subject said "It was challenging to be at practice and want to help and not be able to tackle and stuff.” Another athlete talked about self challenge by stating "I still participated in the drills that I could assist in so that was challenging to get over my fear of being hit again.”

Most of the task appreciation came from either their teammates or coaches as indicated by six of the participants. The athlete's teammates were said to “appreciate me when I show up to practice to help out”, and "I got appreciation at the same time because everyone was happy that I was back.” Three of the participants mentioned that they received task appreciation from their athletic trainer because they did all of the exercises they needed to do to get better. Four of the seven subjects mentioned how their coach appreciated what they were doing. One of the subjects reported that "I know that the coach appreciates me when I show up to practice to help out.” The four athletes that did mention their coach said they could tell that their coach was appreciative that they still came to practice even though they could not participate at full strength. When talking about coach appreciation one subject said "And then coaches gradually let me on the ice just to skate and telling me that I was improving and getting strength back and stuff like that was helpful.” Another subject described their coach’s support by stating,

Um just like whenever I would go to practice injured, our coach use me to help out and stuff and he appreciated that I was there. He had me stand in drills and hold pads so I could still actively participate so that was good. So I would be there and still get his feedback and see what is going on and learn stuff. I think that he trusted that when I said I need to stop then he would know that I would 
need to stop. I mean so he runs practice like he would if I was in perfect health. I know that I need to stop and I know that he respects that.

Five of the athletes were grateful that their coaches still allowed them to participate in practice even though on a limited basis. The athletes said that it helped them still feel connected to the team even though they would not be participating in the entire practice.

\section{DISCUSSION}

This study explored club sport athletes perception of social support during injury rehabilitation. The purpose of this study was to determine the perceived social support systems that are used after an athletic injury and who provides each type of support for club sport athletes. It also investigated differences in support received among these club sport athletes. Although other studies were performed using collegiate athletes, club sport athletes are a population that is relatively unstudied. This studied illustrated that the participants were in fact aware of their social support network and how to utilize them throughout their injury rehabilitation. Their perception of who was in their social support system was similar, but the type of support considered to be most important as well as who provided them with that support was different among the seven club sport athletes in this study.

The results from this study indicate that athletic trainers do play an important role in the social support network of club sport athletes, especially during injury rehabilitation. According to the questionnaire athletic trainers provided the most listening support to the participants, and the importance of their role is also reiterated in the interview. Six of the seven athletes mentioned their athletic trainer as one of their top three providers of social support. The interview also indicated that athletic trainers 
provided emotional support, task appreciation, and personal assistance. Club sport athletes rarely have athletic training coverage, with the exception of the athletes in this study. This indicates having the presence of athletic trainers may be beneficial to injury recovery to club sport athletes.

Anther recurring theme found both in the questionnaire and in the interview was who the athletes reported as their social support network. The same four groups of individuals were indicated at some point during participation in this study. The individuals mentioned were athletic trainers, coaches, family, and teammates/friends. The types of support they provided differed among the participants, but the same group of individuals was mentioned by them in both the interview and the questionnaire. The questionnaires asked the athletes to list 2 groups of people who provided them with the most social support and the interviews asked them to talk about 3 different individuals as well.

These participants also indicated that their coach provided them with the majority of task appreciation and task challenge in both the questionnaire and the interview. The unique aspect was that the task support was not stemming from what they were doing in rehabilitation, but from what they were still able to do at practice with the team. The participants felt their coaches didn’t ask about their injury often but showed appreciation when the athletes came to practice although they couldn't participate to the best of their ability. It was really important to the athletes that the coaches made an effort to keep them connected to the team. It didn't seem to matter that their coaches rarely provided listening or emotional support because they greatly appreciated the task appreciation and task challenge that came from their coach. 
It was hypothesized that club sport athletes would rank athletic trainers as important providers of listening support, coaches would provide task appreciation and task challenge, and that teammates would provide reality conformation and emotional support. Based on the responses to the questionnaire only a few of these hypotheses could be confirmed. Athletic trainers were ranked the highest for providing listening support. Coaches were also reported to have provided the most task appreciation and task challenge in both the questionnaire and the interview. Teammates were not indicated to have been important providers for any type of support according to the social support questionnaire but they were frequently mentioned in the interview. The participant's family was reported to provide emotional support and tangible assistance. The results for emotional challenge, reality conformation, and personal assistance varied among the participants, but only in the questionnaire. The interview mentioned many providers of these types of social support, that wasn't indicated in the questionnaire. Rosenfeld et al. ${ }^{10}$ researched social support using 170 NCAA Division I athletes and found that their coaches were reported to provide task challenge primarily and task appreciation secondarily. The results with the club sport athletes are similar, even though they are different in many ways from Division I athletes. This same study reported that teammates were reported to have provided task challenge appreciation primarily and listening support and reality conformation secondarily. They also found that family provided task appreciation and like this study, emotional support as well. As was reported in this study, coaches were not listed to have provided listening support, emotional support, or reality conformation. Even though club sport athletes are not a 
studied population in research, the study by Rosenfeld et al. shows similar results in who provides certain types of support.

Other studies have indicated similar findings. A study by Robbins and Rosenfeld ${ }^{1}$ again using 35 Divisions I athletes reported that they felt their coach provided more task challenge pre-injury then during their time spent in rehabilitation. Club sport athletes also mentioned that their coaches provided task support only in practice as well, although they never mentioned if they received it at practice pre-injury. The athletes also indicated that they were more satisfied with the support that they received from the athletic trainers than from their coaches. The injured athletes in Robbins and Rosenfeld's ${ }^{1}$ research perceived that their athletic trainers listening support, task appreciation, task challenge, and emotional challenge are more influential to their well-being than support from their coaches. Athletic trainers were listed as important providers to club sport athletes as well, but it was never indicated that their support was more beneficial to them then their coaches. The results from this study on club sport athletes is somewhat similar in regard to listening support in that $71.4 \%$ of the athletes reported that their athletic trainer provided the most listening support during their injury rehabilitation. However, this study reported that task appreciation and task challenge during their rehabilitation came from their coaches rather then their athletic trainers.

The type of support that is most commonly given by an athletes family is emotional support and tangible assistance. ${ }^{17,18}$ The results from this study also confirm those findings as $57.1 \%$ of the subjects said their family provided the most emotional support and $85.7 \%$ reported that their family provided them with the most tangible assistance. In college, athlete’s teammates may take on a more important role in their 
social support network when compared to their family and friends. Most of their time and experiences are spent with each other. Teammates are found to provide reality conformation by giving the athlete someone that they can identify with and share their common experiences. ${ }^{17,19}$ An athletes teammates have also been found to provide emotional support by serving as a constant challenge to their emotional state and also offer some form of tangible assistance. ${ }^{18}$ However, that was not apparent with the club sport athletes as their teammates were not indicated to be important providers for any type of social support according to the questionnaire. The interview, however, indicated the participants teammates provided listening support as well as reality conformation. The ability to relate to their teammates and know that they have gone through the same experience was very helpful to these club sport athletes.

The participants in this study were asked to rank, from importance, the eight types of social support in the questionnaire. The results varied among the seven participants as to what type of social support was most important. The interview also reflected the variety of social support that was provided to these club sport athletes. The only type of social support that the club sport athletes indicated that they didn't really receive was tangible assistance, which included any financial support. Research by Bone and Fry ${ }^{11}$ found that their 57 Division I athletes reported listening support as the most important type of social support. Therefore, it may be difficult to determine, using club sport athletes, what type of social support is perceived as most important. It may also indicate that we may just be dealing with seven unique individuals with different personalities and views on what type of social support is more beneficial to their well-being. The athletes all coped with their injury, but in different ways. It is important $t$ to be aware that not all 
athletes need the same type of support, especially if you play a role in many athletes social support systems.

In order to tease out more information than what was found in the questionnaire, an interview was obtained during the second week of rehabilitation. The interview started by having the athletes talk about how they were coping with their injury. The way in which an athlete may cope with their injury varies from one person to the next, depending upon how they perceive various stressors. The participants did not have any problems coping with their injury. Many of them reported that it was hard to be at practice and not be able to contribute to their team but they were able to deal with it successfully. They coped with that hardship by still participating in drills at practice and talking to their teammates about their frustrations. All of these athletes used the approach coping style because they confronted the source of stress and made deliberate attempts to reduce it. ${ }^{5}$ Approach coping can also be described as problem-focused coping because it is generally used by athletes who perceive they have control over the situation. ${ }^{19}$ Crocker and Graham ${ }^{20}$ used 377 competitive athletes at a variety of levels and found that their athletes primarily used problem-focused coping. The results from this study support their findings because these subjects felt the stress of being injured and instead of ignoring it they took steps to maintain control and remain connected with the team. However, Crocker and $\mathrm{Graham}^{20}$ reported that self-blame was also frequently used by the athletes. Although some of the findings are similar to this study, the athletes in this study did not participate in any self-blame when coping with their injury.

Research by Johnston ${ }^{21}$ using 16 collegiate athletes found that immediately after an injury they were often shocked and in disbelief of the situation. It wasn't until week 
one that the athletes reported feeling anxiety about the injury as well as frustration and depression when they were unable to accomplish pre-injury activities of daily living. The athletes stated that the main trigger of negative response towards an injury was watching others play their sport. The interviews with the club sport athletes indicated that they were never in disbelief over the situation. They did state that the hardest part about being injured was going to practice and games and not being able to participate and contribute to their team. One of the main findings from the interview that was similar to Johnstons ${ }^{21}$ study was that the athletes felt frustrated with certain activities of daily living while injured. The fact that most collegiate athletes are participating in their sport under scholarship may add to the stress and devastation after an injury. The club sport athletes never felt threatened that they would loose their position on the team, which is could be a reason why all seven participants were able to cope well with their injury.

Tracey $^{22}$ interviewed 10 injured athletes at the Division III level about their emotional response to an injury. Their athletes reported that the most difficult part of recovery was attending practice and games without being able to participate. Club sport athletes in this study also reported this to be the number one cause of frustration. The athletes in Tracey's ${ }^{22}$ study also mentioned that the way they emotionally responded to their injury is highly influenced by how their athletic trainer reacts to it. The athletes in this study mentioned how much they appreciated the help of their athletic trainer. They also stated that their athletic trainer was a very important provider of social support pertaining to their injury rehabilitation. The athletes from both studies also mentioned that they were willing to do whatever it takes to recover and return to activity. 
Maintaining involvement in their sport, encouragement, listening support, and understanding are important aspects to social support according to the club sport athletes in this study. All club sport athletes mentioned that they still went to practice and participated as best as they could, which helped them deal with not being able to play. They also stated that their teammates, athletic trainer, and coach were always asking how they were doing and willing to listen when they talked about their injury. This is somewhat similar to the social support identified by the athletes in the Ford ${ }^{2}$ study. The social support identified was encouragement, reassurance, advice, maintaining involvement, personal assistance, and financial assistance. Although some were not indicated as essential by the club sport athletes in this study, both studies rate encouragement and maintaining involvement as important types of social support.

According to the subjects in this study, listening support and emotional support were very important aspects of social support. Although not ranked high in the questionnaire, the club sport athletes reported in the interview that they received the majority of their listening and emotional support from their teammates. However, based on the questionnaire and the interview athletes reported that their athletic trainer also provided them with listening and emotional support. Only one of the athletes in this study mentioned their coach when talking about listening and emotional support. This athlete mentioned that their coach was not an emotional person and that they assumed that there was support even though he may not show it. A few of the athletes stated that their coach did not show any listening or emotional support, they just wanted to know when they would return. 
The participants mentioned getting task appreciation and task challenge from their teammates, athletic trainer, coach, and from within themselves. Most of the task challenge was from being at practice and getting over the fear upon return to the game of being hit again. These athletes challenged themselves through activities of daily living also. Coaches were mentioned for showing appreciation that the athletes still came to practice and the athletic trainers provided appreciation to the athlete for doing their exercises during rehabilitation.

\section{Clinical Relevance}

Although a limitation to this study was the small sample size, this study did indicate how important the role of an athletic trainer can be to an injured club sport athlete. The athletic trainer was often mentioned in the interview, although this can be seen as a bias because it was conducted by the athlete's athletic trainer in an athletic training setting. All of the athletes appreciated the help and support they received from their athletic trainer.

However, although not reported in this study, are athletic trainers ready to take on that role? A study by Washington ${ }^{24}$ reported that $45.7 \%$ of the athletic trainers that participated and completed a questionnaire reported that they could assist in the psychological recovery but in a limited capacity. Of these athletic trainers, $68 \%$ responded that they were comfortable with the knowledge they had on the psychological aspects of rehabilitation. Athletic trainers do play a role in a club sport athletes social support network. After knowing this it may be important to find out if athletic trainers are receiving enough psychological training to help support their athletes. Athletic trainers do not need to know how to deal with their athletes psychological problems, but 
they may need to know how to point their athletes in the right direction for help. Playing a role in an athletes social support system indicates the responsibility to know what to do and where to refer your athlete if needed. Anyone involved in a social support network needs to be aware of the psychological needs of their athletes and be able to refer if their involvement is out of their knowledge or comfort level.

Although other studies were performed on collegiate athletes, club sport athletes is a population that is relatively unstudied. There are multiple factors that can differentiate collegiate athletes from club sport athletes. For one club sports are not supported or recognized by the university. Scholarships and other financial assistance do not pertain to club sport athletes as it would to most collegiate athletes. In general athletes join a club sport to learn new skills, enhance skills they already have, meet new people, stay fit, and travel to different universities. Club sports are organized and administered by students and each club has an advisor to provide guidance. Club sport teams report to the Office of Campus Recreation and each team must be registered with Student Organization Services. Club sport athletes may not have as an extensive social support network as other collegiate athletes. Most club sports do have a head coach, but rarely an assistant. Coaches for club sports do not get paid, it is purely voluntary. Club sport teams also do not have their own team physician, and most teams do not even have an athletic trainer to cover their sport. The reason that all the athletes in this study mentioned their team, coach, and athletic trainer may be because they are the only other people that are involved in their injury rehabilitation. This study may be a start in expressing the need for athletic training coverage for club sport teams. Club sport athletes can sustain the same injuries and emotional stress as any other collegiate athletes. 
The presence of a more extensive social support network, such as having an athletic trainer, can be very beneficial to club sport athletes. This was apparent as all seven club sport athletes stated that athletic trainers were important social support providers during injury rehabilitation.

These athletes did not unanimously specify certain types of social support that they felt to be most important. This could just indicate that these seven athletes are all very unique in their preferences and experiences. The fact that the athletes find different types of social support to be more important just reiterates that not one athlete is the same. These athletes did not rank the same types of support which shows that we cannot treat and respond to all of our athletes in the same way. All seven individual athletes were injured and worked towards the same outcome, although their individual paths to return to play were different.

\section{CONCLUSION}

The purpose of this study was to determine the perceived social support systems used after an athletic injury to a club sport athlete and who provides each type of support. It was found that club sport athletes do receive sufficient support from their social support network. The athletes were also found to be aware that they have a social support network to help them cope. For the most part, athletes were satisfied with the social support they have received during injury rehabilitation.

Although not one type of social support was indicated as most important by these athletes, individuals involved in injury rehabilitation were regarded as most important. Athletic trainers are the most important providers of listening support, while the coaches were indicated to provide the most task challenge and task appreciation. The family was 
indicated as important providers of tangible assistance and emotional support. Seventy one and four tenths percent of the athletes reported that athletic trainers were one of the two most important people who provided social support throughout the injury process. The others varied between family, teammates, and coaches.

Social support is important to injured club sport athletes. As a provider in that social support network, athletic trainers, coaches, teammates, and family need to be aware of the roles they play. The athletes in this study simply indicated that being there to listen and understand what they are going through is the most helpful to them. Once they know that those providers are there for them, it is easier for the athlete to concentrate on the other aspects of injury rehabilitation. 


\section{REFERENCES}

1. Robbins JE, Rosenfeld LB. Athletes' perceptions of social support provided by their head coach, assistant coach, and athletic trainer, pre-injury and during rehabilitation. J Sport Behav. 2001;24(3):277-298.

2. Ford IW, Gordon S. Coping with sport injury: resource loss and the role of social support. J Persl Interper Loss. 1999;4(3):243-257.

3. Park JK. Coping strategies used by Korean national athletes. Sport Psych. 2000;14:63-80.

4. Storch EA, Storch JB, Killany EM, Roberti JW. Self-reported psychopathology in athletes: a comparison of intercollegiate student-athletes and non-athletes. J Sport Behav. 2005;28(1):86-97.

5. Anshel MH, Porter A, Quek JJ. Coping with acute stress in sport as a function of gender: an exploratory study. J Sport Behav. 1998;21(4):363-376.

6. Anshel MH, Raviv S, Jamieson J. Cognitive appraisals and coping strategies following acute stress among skilled competitive male and female athletes. $J$ Sport Behav. 2001;24(2):128-144

7. Yi J, Smith R, Vitalion P. Stress resilience, illness and coping: a person-focused investigation of young women athletes. J Behav Med. 2005;28(3):257-265.

8. Raedeke TD, Smith AL. Coping resources and athlete burnout: An examination of stress mediated and moderation hypotheses. J Sport Exerc Psychol. 2004;26(4);525-541.

9. Rees T, Ingledew DK, Hardy L. Social support dimensions and components of performance in tennis. J Sport Sci. 1999;17:421-429.

10. Rosenfeld LB, Richman JM, Hardy CJ. Examining social support networks among athletes: description and relationship to stress. Sport Psychol. 1989;3(1):23-33.

11. Bone JB, Fry MD. The influence of injured athletes' perceptions of social support from ATCs on their beliefs about rehabilitation. J Sport Rehabil. 2006;15:156-167.

12. Barefield S, McCallister S. Social support in the athletic training room: athletes' expectations of staff and student athletic trainers. J Athl Train. 1997;32(4):333338. 
13. Johnston LH. The provision of social support to injured athletes: a qualitative analysis. J Sport Rehabil. 1998;7(4):267-284.

14. Richman, J.M, Rosenfeld LR, Hardy CJ. The social support survey: a validation study of a clinical measure of the social support process. Research Soc Work. 1993;(3);288-311.

15. Henert, SE. Exploring injured athletes ratings of social support and use of coping strategies as a function of injury type and gender over the course of rehabilitation. Dissert Abst Inter: Sect B: The Sci and Engineer. 2000;61(3-B):1695-1778.

16. Kestner, M. Social support systems during athletic injury recovery in collegiate football athletes. Research Project for West Virginia University, 2006.

17. Morgan TK, Giacobbi PR. Toward two grounded theories of the talent development and social support process of highly successful collegiate athletes. Sport Psychol. 2006;20:295-313.

18. Udry E. People helping people? Examining the social ties of athletes coping with burnout and injury stress. J Spor Exerc Psychol. 1997;19:368-395.

19. Kimball A, Freysinger VJ. Leisure, stress and coping: the sport participation of collegiate student-athletes. Leisure Sciences. 2003;25(2-3):115-142.

20. Crocker PRE, Graham TR. Coping by competitive athletes with performance stress: gender differences and relationships with affect. Sport Psychol. 1995;9:325-338.

21. Johnston LH, Carroll D. The context of emotional responses to athletic injury: a qualitative analysis. J Sport Rehabil. 1998;7:206-220.

22. Tracey J. The emotional response to the injury and rehabilitation process. $J$ of Appli Sport Psych. 2003;15:279-293.

23. Gould D, Udry E, Bridges D, Beck L. How to help elite athletes cope psychologically with season-ending injuries. Athl Ther Today. 1997;2(4):50-53.

24. Washington-Lafgren L, Westerman BJ, Sullivan PA, Nashman HW. The role of the athletic trainer in the post-injury psychological recovery of collegiate athletes. Intern Sports J. 2004;8(2):94-104. 
APPENDICES 


\section{APPENDIX A}

\section{THE PROBLEM}

\section{Research Question}

It is always a concern for athletic trainers to improve the physical aspect of the rehabilitation process, while the psychological aspects are often overlooked. Social support, not only from the athletic trainer, but from their teammates, coaches and outside influences as well, play an intricate role on how the athlete will be able to cope with their injury. The athlete's ability to utilize their support and cope properly with their injury is a complex part of the rehabilitation process. So would the athletes own knowledge of the support system that surrounds them influence their psychological recovery from an injury? If so, it is our responsibility as athletic trainers to educate our athletes and coaches, as well as others, on the importance of the psychological aspect of the injury rehabilitation process.

Coping success in sport includes the athlete regaining composure, establishing a

proper mental set, and maintaining optimal arousal and concentration. ${ }^{25}$ It is our job as athletic trainers to be able to educate our athletes on the importance of coping properly. The ability for an athlete to cope with their injury at hand can be directly related to the social support they receive from others. Social support has been found to be an important tool for enhancing an athlete’s psychological recovery. ${ }^{12}$ Their social support system may include their teammates, coaches, athletic trainers, media, family, and friends, among others. Many times there are people involved in this support system that the athlete may not be aware of. The social support system is an important influence in the coping strategies of the athlete. It is important for the athlete to know who they can turn 
to and trust when they are dealing with stress, not only from injury, but from any stressors throughout sport participation.

An athlete’s ability to completely and successfully use their own social support group depends on multiple factors. Their status on the team, leadership qualities, team involvement, and communication skills are determining factors whether the athlete will utilize their social support. ${ }^{2}$ Taking advantage of the social support system is something that the athletes do not realize as a possibility for improving their injury rehabilitation process. All athletes cope in some way with their injury, but not all coping is healthy during the process of rehabilitation. One question that I wish to answer is whether collegiate club sport athletes are aware that social support systems are available to provide assistance to enhance their coping process.

It is my experience that most athletes that I have come in contact with are not aware that there is a psychological aspect to the rehabilitation process. After a year of working with club sport athletes I realized that there are few colleges that provide certified athletic trainers as a resource for these teams. My familiarity with these athletes sparked my interest as to whether they understand what social resources are out there for them. Many athletes, depending on their sport and status on the team, do not access the positive support they could attain from using their social support system. Most athletes as well as athletic trainers may not know who makes up their support system and how to attain its benefits. It is an important question to ask whether knowing and utilizing the surrounding social support will affect how the athlete copes with their injury. The success that the athlete may have in rehabilitation may also be due to attaining psychological help from their social support. 
Most research conducted on the psychological aspects in injury rehabilitation used collegiate or elite athletes. There is little research performed using collegiate athletes that participate in club sports verses NCAA approved sport teams. The reasons athletes participate in club sports may be different compared to other collegiate athletes. Along with different reasons for participation, there may be alternate social support systems as well as coping strategies to similar injuries. Therefore my research questions are: Do these collegiate club sport athletes know that there is a social support system out there for their convenience? Who do these collegiate club sport athletes perceive to provide them with social support? Does the athletes' gender or the sport they play affect their perception of their social support system? And finally: Is there a certain type of support that is perceived to be given by a specific member of the social support system? Experimental Hypotheses

1. Certified athletic trainers will play an important role in providing listening support to collegiate club sport athletes based on the responses from the questionnaire.

2. Coaches will play an important role in providing task challenge and task appreciation to collegiate club sport athletes based on the responses from the questionnaire.

3. Teammates will play an important role in providing reality conformation and emotional support to collegiate club sport athletes.

4. Athletic trainers and teammates will be listed as important people who have provided support.

5. Listening support, emotional support, reality confirmation, and personal assistance will be ranked as most important to the club sport athletes based on the responses from the questionnaire. 
Assumptions

1. The participants in this study will respond honestly to the questions in the questionnaire.

2. The participants in this study will respond to the questionnaire to the best of their ability.

3. The survey will be valid and reliable.

4. The questionnaire will accurately relate to the importance of social support.

5. The participants will sustain an injury during the length of the study.

Delimitations

1. Participants were members of collegiate club sport teams.

2. Participants represented the club sports of ice hockey and rugby.

3. Participants were between the ages of 19-23.

Operational Definitions

1. Athletic Injury - An injury that occurs during sport competition or practice that keeps the athlete out of athletic participation for a period of time.

2. Burnout - When athletes feel physically and psychologically exhausted from the demands of training and competing, perceive a reduced sense of accomplishment and experience sport devaluation in which they stop caring about sport and their performance. $^{8}$

3. Certified athletic trainer - A professional health care provider, who specializes in evaluating and treating athletic injuries.

4. Club sports - Sports programs that are organized and administered by students of the university that provide opportunities to learn a new sport or enhance skills and provides no scholarships.

5. Coach - The person on the team responsible for making decisions and for training the players for competition.

6. Coping - Any conscious effort to deal with stressful demands that consists of learned behavioral responses and lowers stress by limiting the importance of a dangerous or unpleasant condition. ${ }^{1,27}$ 
7. Coping style - Methods of coping that characterize the individuals' reactions to stress either across different situations or over time within a given situation. ${ }^{26}$

8. Coping resources - Comprise a variety of behaviors and social networks that aid the individual in dealing with the problems, joys, disappointments, and stresses of life. ${ }^{8}$

9. Defensive high-anxious coping - Category with high trait anxiety and high social desirability. $^{29}$

10. Denial - Unconscious effort to protect oneself from potentially painful information. $^{30}$

11. Emotional challenge - Perceived challenge to help the recipient to evaluate his or her attitudes, values and feelings. ${ }^{1,12}$

12. Emotional support - Another individual provides comforts and indicates that he or she is on their side. ${ }^{12}$

13. High-anxious coping - A category with high trait anxiety and low social desirability. $^{31}$

14. Listening support - The perception that another is listening without giving advice or being judgemental. ${ }^{12}$

15. Low-anxious coping - A category with low trait anxiety and low social desirability. $^{29}$

16. Moderator variable - Qualitative or quantitative variable that affects the nature, the direction, or the strength of a relation between and independent and dependent variable. $^{8}$

17. Personal assistance - Another individual provides services or help, such as running an errand or driving them somewhere. ${ }^{12}$

18. Reality conformation - Support from someone similar to the recipient that helps by confirming their perspective on the situation. ${ }^{1,12}$

19. Repressive coping - Category with low trait anxiety and high social desirability. ${ }^{31}$

20. Social desirability - The need of an individual to respond in a culturally appropriate and acceptable manner to gain social approval, the tendency to deny socially undesirable traits while claiming socially desirable ones, and the tendency to protect ones self-esteem from ego threat. ${ }^{29}$ 
21. Social support - The presence of others whom athletes can rely on and whom they know value and care for them. ${ }^{8}$

22. Social support system - Includes coaches, teammates, friends, family, and athletic trainers, in which all have different responsibilities.

23. Stress - Experienced when people perceive situational demands to exceed their coping resourses. ${ }^{2,30}$

24. Tangible assistance - Another individual provides the recipient with financial assistance, products, and/or gifts. ${ }^{12}$

25. Task appreciation - Another individual acknowledges the recipients efforts and expresses appreciation for their work. ${ }^{12}$

26. Task challenge - Another individual challenges the way of thinking about a task or activity to lead them to greater creativity, excitement, and involvement. ${ }^{12}$

27. Teammates - Includes athletes that participate on the same sport team.

\section{Limitations}

1. Participants may not fill out the survey completely.

2. Participant's mood may affect their responses to the survey and in the interview.

3. Participants may not answer the questions honestly as their responses may be what they feel the investigator would like to hear. (Hawthorne effect)

4. The time of day may affect the outcome of the survey responses as well as the interview.

5. Participants may sustain an injury outside of club sport participation.

6. Participants may be bias towards the interviewer.

\section{Significance of the Study}

Very little research has been conducted in comparing the relationship between utilizing a social support system and how it relates to the athlete coping with injury in collegiate club sport athletes. Psychological aspects are something that is often overlooked in the injury rehabilitation process. Many athletic trainers are unaware or 
forget that this is an intrical part to improving rehabilitation. The primary purpose is to educate athletic trainers to increase the awareness that social support systems play an important part in the injury healing process. Along with educating athletic trainers, education for our athletes is important so they will understand the beneficial effects of psychological aspects in injury rehabilitation.

Athletic trainers role in the social support system are as psychological caregivers to their athletes. This study will demonstrate the importance of our role in coping support as well as the roles of others in the social support system. It will also inform us on the importance athletes place on their social support group and how well they are utilized. This study will also aid in increasing awareness to improve individual coping and acceptance of their injury by making the athletes aware of whom they can turn to for social support. There is no current literature that has examined the social support system of recreational club sport athletes. This study will provide knowledge of social resources available for the club sport athlete.

It is essential to show the need for social support to athletes and how it can help them cope with their injury rehabilitation. This study will illustrate what social support systems are available for injured collegiate club sport athletes and whether they are aware of how to use them as their aid in rehabilitation. More importantly, this study will demonstrate the importance of utilizing the social support system in the rehabilitation process. 


\section{APPENDIX B \\ LITERATURE REVIEW}

Introduction

Injuries are inevitable for most athletes and they are forced to cope in any way they can. The important aspect to realize is that they are not in it alone. For most athletes the psychological aspects of sport participation can be a troubling experience, especially when it comes to coping in injury rehabilitation. Approximately 3.5 million sport and recreational injuries occur each year among American athletes. ${ }^{1,11,32,33}$ As many as eight out of 10 athletes are injured at some point during their high school and college careers. ${ }^{1}$ Most of these injuries may be physical in nature and occur because of some biomechanical alteration. However, multiple psychosocial factors may also contribute to injury vulnerability and may be threatened or lost during this time. Some of the important psychosocial resources that athletes may lose are team status, personal characteristics, rewards, and/or group membership and social ties. ${ }^{2}$ Injuries in general have the possibility to threaten the athlete’s self-concept, belief system, social functioning, values, commitments, and emotional equilibrium. ${ }^{2,34}$ An athlete’s psychological response to an injury depends on their prior psychological level, the nature of the injury, and what the disability will mean to the athlete. ${ }^{35}$ It is important for the athletic trainer as well as the athlete, coach, and others involved in the rehabilitation to understand the variety of emotions that the athlete may experience during their injury and throughout recovery. The athletic trainer is most often the injured athletes' first contact 
within the health care system. The athletic trainers' role in the athletes' social support system is just as important as coaches, teammates, family, and friends.

Social support is often defined as information from others that one is loved and cared for, esteemed and valued, and part of a network of communication and mutual obligation. ${ }^{2,12,29}$ Social support can come from family, friends, coaches, sport psychology professionals, physical therapist, and athletic trainers. ${ }^{11,17}$ The role of a social support system is a very important factor in coping with injuries. The social support systems emotional response to an athletes injury may influence the type of response the athlete uses to cope with the injury. ${ }^{36}$ Not only can the inability to cope in the proper way affect the outcome of rehabilitation, ineffective coping along with acute stress tends to predict burnout and the athletes withdrawal from competitive sport. ${ }^{5,25}$ Coping successfully in sport involves regaining composure, establishing a proper mental set, and maintaining optimal arousal and concentration. ${ }^{28}$ Athletes expect and need to receive social support from athletic trainers, and athletic trainers must realize that an athletes needs go beyond just physical care. The review of the literature will further address the following topics: athletic stress; coping styles and resources; emotional responses; psychology of injury; and social support.

Athletic Stress

Individuals strive to create a world in which they feel protected, comfortable, loved, and esteemed. ${ }^{2}$ Any stress that an athlete may encounter in college or sport can have a negative affect on this world. Stress in the sporting arena may be a result of repeated sport experiences that are perceived as stressful, unrewarding, or having

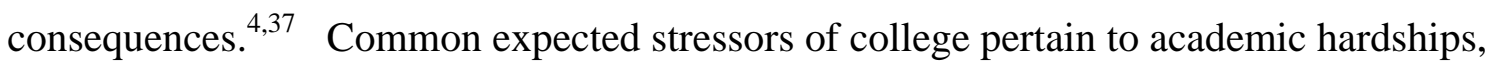


forming peer relations, and facing financial constraints. ${ }^{4}$ Athletes who are moving on to the collegiate level often become overwhelmed, isolated, lonely, and are confronted with new responsibilities. ${ }^{38}$

Stress has been defined as a reaction to the environment in which there is a perceived threat of a net loss of resources or a perception that an investment of resources is not producing a net gain. ${ }^{2}$ Stressors like errors, penalties, unpleasant comments from spectators, increases in competition levels, competition for positions, and beginning new relationships can negatively influence the cognitive and psycho-physiological processes. ${ }^{4,6}$ One study ${ }^{18}$ found that athletes who are under stress are more likely to view their interactions with others as being negative, rather than positive or neutral.

Stress can also be defined as an experience when people perceive situational demands to exceed their coping resources. ${ }^{18,32}$ Athletes often have to deal with acute stress in sport, which is a persistent feature that consists of time-limited and short-term events. Acute stress can range from making an error in competition or receiving a penalty from an official. It is also important not to overlook long term stressors that athletes may encounter, such as dealing with an injury. An injury can be stressful and this stress can impede the rehabilitation process. ${ }^{24}$

Anderson's ${ }^{39}$ results reported that peripheral narrowing that occurs during the stress response may indeed be one of the mechanisms by which an injury can occur. He distributed a questionnaire to 196 male and female NCAA Division I athletes and also found that major life events, along with peripheral narrowing, can leave an athlete vulnerable to stress and prone to a high stress response. Stress is not a simple variable, but is a system of processes that includes appraisal and coping, which mediate the 
frequency, intensity, duration, and type of psychological and somatic response. ${ }^{27}$ Some risk factors for stress are gender, previous history, personality traits, attitude, response to the event, and current medical problems.

A study on collegiate football players by Albison ${ }^{40}$ found a significant relationship between life event stress and mood disturbance after an injury. She reported that the greater a perception of a negative life event stress predicted greater post-injury mood disturbance immediately after the occurrence. Athletes who reported greater coping difficulties also reported greater perceptions of stress. Albinson ${ }^{40}$ also noted that athletes with a higher perception of stress at day four of an injury reported greater difficulty in coping with the injury at day seven.

Stress has been linked to be a causal factor in injury and illness. The way an athlete may perceive a stressor can affect their physical health and can lead to unhealthy behaviors. These behaviors can range from substance abuse, decrease in physical activity, poor health, poor academic performance, lack of problem solving abilities, and a low utilization of social support networks. ${ }^{37}$ The General Adaptation Syndrome is a theory used to define how stress can influence physical health. ${ }^{37}$ It states that chronic perceived stress results in prolonged physiological arousal which leads to physical exhaustion and thus increasing vulnerability to illness, disease, and injury. ${ }^{37}$

Every year over two million Americans sustain injuries severe enough to require inpatient hospitalization. ${ }^{30}$ Many of these individuals develop injury-related distress, including posttraumatic stress, depression, anxiety, and pain. ${ }^{30}$ Not everyone exposed to a traumatic injury develops a stress disorder. The way in which one copes with the injury can greatly influence the long and short-term emotional adjustments that are made as well 
as lessen the burden associated with injury. Self-esteem is a psychological resource that influences stress and how the athlete perceives it. Those who have positive views on themselves should be less likely to feel overwhelmed when confronted with stressful demands than those who do not have positive views. ${ }^{41}$ The study by DeLongis ${ }^{41}$ on 75 married couples found that person's with low self-esteem and low emotional support had a higher probability of a positive association between stress and both physical symptoms and poor mood than did those who were high in these psychological assets.

The inability to cope properly with persistent stress in sport may lead to decreased motivation, emotional distress, poor athletic performance, and eventual psychological burnout and withdrawal from competitive sport. ${ }^{6,26}$ For many athletes the intense physical and psychological demands of the sport can come with a high cost, that being burnout. It has been defined that athletes experiencing burnout feel physically and psychologically exhausted from the demands of training and competing, perceive reduced sense of accomplishment, and experience sport devaluation in which they stop caring about sport and their performance. ${ }^{8,42}$ Athletes who experience burnout are often emotionally exhausted by feeling overwhelmed, emotionally depleted, and have decreased energy levels. ${ }^{42}$ Burnout is thought to have a negative influence on the quality of sport experiences, leading to a decrease in performance and possibly an end to sport participation. $^{8}$ Athletes associate burnout with staleness, fatigue, too much practice, loss of interest, and pressure from coaches, parents and peers. ${ }^{42}$ Not only does burnout affect sport participation, but it influences the athlete's physical and psychological well-being. It is widely known that burnout is a consequence of chronic stress. Although burnout is seen as stress related, some athletes are more susceptible to the negative effects of stress 
than others. This is determined by the personal characteristics and the specific situational factors that the athlete is involved in.

Nichols et al ${ }^{43}$ studied stress among international adolescent golfers and found that the four most frequently reported stressors were making a physical error, making a mental error, observing an opponent play well, and difficult weather conditions. These golfers reported most of their stressors during the days in which two of the most important competitions of the season were taking place.

The study by Rosenfeld et al. ${ }^{10}$ conducted interviews on coaches and their perception of athletic stress. Most coaches responded that they could tell when their athletes are stressed. The most frequently mentioned sign of stress were jumpiness or fidgeting. These coaches mentioned that to help the athlete cope with this stress they would provide encouragement and psych him/her up or offer private counseling away from the team. When asked why they may not listen to an athlete who is stressed they stated that it might lower the team's morale by focusing on the problems of one athlete. They also conducted interviews using the athletes. All of the athletes, except one, stated that feeling stressed is a typical and normal reaction when performing as an athlete. Three female athletes said that they felt proud and happy when they received praise from their coach while the male athletes differed. The male athletes provided three distinct responses: some felt great, some felt embarrassed, and some felt pressured to do more.

Psychosocial moderator variables have been the focus of researchers because of their ability to affect the nature and importance of relations between life stress and personal well-being. ${ }^{32,33,45}$ Identification of these variables may be a possible step in identifying individuals who might be at risk for negative outcomes of life stress. A 
moderator variable is a qualitative or quantitative variable that affects the nature, direction, or the strength of a relationship between two variables. ${ }^{8,32,45}$ There is evidence that social support, sensation-seeking motivation, and internal locus of control are moderator variables that are capable of reducing stress outcomes relations. ${ }^{18}$ Other moderator variables are gender, socioeconomic status, or personality traits that interact with other conditions in producing an outcome. ${ }^{46}$ There are also mediator variables that are generated in the situation itself and change the relationship between the precursor variable and the outcome variable. ${ }^{45}$ In a stressful situation, coping acts as a mediator variable and transforms the original appraisal of the situation and the emotions that were involved.

Coping Styles and Resources

Coping successfully in sport involves regaining one's composure, establishing the proper mental set, and maintaining optimal arousal and concentration. ${ }^{25}$ Coping resources comprise a wide variety of behaviors and social networks that aid the individual in dealing with the problems, joys, disappointments, and stresses of life. ${ }^{8}$ Coping simply means adaptively modifying ones cognitive and behavioral efforts to manage psychological stress. ${ }^{37}$ The style of coping that the athlete chooses is only one component of their response to stress, yet it is a very important one. Most individuals vary their coping efforts and choices to fit a given stressor. Coping skills help protect people from being psychologically harmed by challenging experiences on their life. ${ }^{47}$ Coping strategies help an athlete defend against negative life experiences, which can lead to increased resiliency against injury, and better adherence to rehabilitation if an injury were to occur. Coping resources influence an athlete's ability to deal with the stresses of 
sport participation. The way in which coping will occur depends on the extent to which the individual is satisfied or disappointed with daily support from others. Another important factor affecting why certain coping occurs is the personality of the individual involved and the characteristics of the stressful situation they appear to be in.

Coping is described as learned behaviors that contribute to survival in the face of threatening dangers. ${ }^{46,48}$ The literature contains a variety of coping definitions. One definition of coping is "constantly changing cognitive and behavioral efforts to manage specific external and/or internal demands that are appraised as taxing or exceeding the resources of the person.”3, 20,25,27,43 Another definition of coping is seen as any conscious effort to deal with stressful demands that consists of learned behavioral responses and lowers stress by limiting the importance of a dangerous or unpleasant condition. ${ }^{5}$ There are both internal and external coping resources that help athletes deal with stress. Some examples of internal coping are sleeping patterns, fitness levels, nutrition, and time management. ${ }^{8}$ The perception of receiving strong social support is an external resource that can help the athletes deal with stress.

One major coping strategy that most athletes encounter is denial. Denial is described as an unconscious effort to protect oneself from potentially painful information. ${ }^{30}$ Denial is thought by some to help minimize stress reactions, while others believe that it intensifies the problem by hindering the use of other necessary coping responses. $^{30}$ These needed resources, other than denial, that are deemed useful in most situations are more difficult to initiate as time passes. Another perspective pondered is that denial in fact can be protective and beneficial throughout the early stages of a stressful event but obstruct the effective coping techniques if overused in the long term. ${ }^{30}$ 
Another type of individual coping resource that is often used is self-blame. Attribution of blame and responsibility may be the matter of the athlete keeping control of the situation. Victorson ${ }^{30}$ found that those who blamed themselves experienced more distress during the first few months following their injuries.

Coping techniques usually differ among individuals and how they perceive various stressors. People are thought to be oriented toward using a preferred coping style. Coping styles are methods of coping that characterize individuals' reactions to stress either across different situations or over time within a given situation. ${ }^{6}$ An individual's choice of a coping style reveals their tendency to react in a predictable manner within a specific situation. Coping style has been divided into approach categories or avoidance categories. ${ }^{5,6}$ Approach coping has also been called sensitization, engagement, or attention coping. ${ }^{25}$ The approach coping style includes confrontation of the source of stress and deliberate attempts to reduce it. ${ }^{5}$ This type of coping is initiated by anger, which motivates confrontation or attack. ${ }^{46}$ Avoidance coping is also labeled repression, disengagement, or rejection. ${ }^{6}$ The avoidance style of coping involves the shunning of anxiety-inducing stimuli and their consequences. ${ }^{5}$ These coping behaviors are initiated by fear, which motivates the behavioral response of avoidance or escape. ${ }^{46}$

Approach coping consists of active steps taken to alleviate the effects of the stressor and may include initiating direct action, increasing ones efforts, and seeking information to explain the source of stress or to prevent its recurrence. ${ }^{5,6}$ This coping style is usually preferred when a situation is controllable, the source of the stress is known, or outcome measures are long-term (e.g. attending to a source of pain is 
preferable to risking a more serious injury) ${ }^{5,6}$ Approach coping is more effective when action is required while ignoring distracting, irrelevant information.

Some situations may require a coping response that will ignore or discount the stressor. These situations may leave the athlete in a position where they cannot afford to be distracted or de-motivated if a stressor, such as an umpires "wrong” call, occurs. Avoidance coping should be used when emotional resources are limited (e.g. low selfesteem), the source stress is not clear, a situation is uncontrollable, or outcome measures are immediate or short-term. ${ }^{27,28}$ Avoidance coping style includes seeking out others as a distraction or engaging in another task rather than the task at hand. ${ }^{27,28}$ Avoidance coping seems to protect the athlete against distracting thoughts and actions in situations that require immediate decisions. ${ }^{27}$

Approach and avoidance type coping are not always used independently, in fact people may alternate between the two in the same situation. For example, certain aspects of a threatening situation, such as a rowdy spectator, should be avoided while other aspects should be approached by notifying security. ${ }^{27}$ The coping technique that an athlete chooses is influenced by the coping style that they attain. One study ${ }^{27}$ found that athletes who used avoidance coping styles exhibited less state anxiety following acute stress than did those who used the approach coping style.

Coping styles have been further divided into four groups: low-anxious, repressive, high-anxious, and defensive high-anxious coping. ${ }^{27,31}$ Low-anxious coping involves low trait anxiety and low social desirability. ${ }^{31}$ The repressive style has low trait anxiety and high social desirability while high-anxious coping has high trait anxiety and low social desirability. ${ }^{31}$ And lastly, defensive high-anxious coping involves high trait anxiety and 
high social desirability. ${ }^{29}$ The athletes who used the repressive style mostly resembled avoidance coping. ${ }^{27}$ In that study the repressors reported higher self-confidence than the low-anxious athletes and the high-anxious and defensive high-anxious athletes reported the highest cognitive anxiety and the lowest self-confidence.

Other attempts at explaining the process of coping have been centered on problem-focused and emotion-focused coping strategies.20,,$^{27,38,43,47}$ Problem-focused coping is coping that is directed at managing or altering the problem that is causing the distress. ${ }^{19,20,27,38,43,47}$ Problem-focused coping is generally used by athletes who perceive that they have control of the situation. ${ }^{19}$ This type of coping may be directed at the environment, like altering pressures, or at the self, like changing goals. ${ }^{25}$ Problemfocused coping is more effective when coping with a situation that is an anticipated stressor. ${ }^{41}$ Some examples of problem-focused coping are seeking social support, actively avoiding the stressor, social engineering, or becoming vocally assertive. ${ }^{25,47}$ Social engineering is creating a physical distance between oneself and the stressor. ${ }^{25}$ Problem-focused coping changes the person-environment relationship by changing either the person, the situation, or both. ${ }^{20}$ Emotion-focused coping consists of regulating ones emotions to reduce or manage cognitive distress. ${ }^{19,20,25,38,43,47}$ Emotion-focused coping relates to the use of cognitive strategies to facilitate the coping process. ${ }^{25}$ This type of coping is more effective when coping with a situation that involves harm or loss. ${ }^{41}$ These strategies may include self-talk, imagery, avoidance, weighing the alternatives, wishful thinking, denial, venting and psychological discounting. ${ }^{20,47}$ Emotion-focused coping can be effective in reducing stress by diverting attention away from the situation (wishful thinking) or by changing the meaning of the situation (cognitive reappraisal). ${ }^{20}$ 
One study ${ }^{7}$ found that athletes who remained healthy after a life stressor favored problem-focused coping. Research on 377 male and female competitive athletes found that athletes primarily used problem-focused coping. ${ }^{20}$ This type of coping involved increasing effort, planning, active coping, and suppression of competing activities. ${ }^{20}$ Self-blame was also used frequently by these athletes as well. ${ }^{20}$ Self-blame can be considered a part of problem-focused coping because it helps the athlete accept the responsibility for their performance problems. ${ }^{20}$

As mentioned before personality plays a role in the type of coping response that is used. Personality can also be linked to the likelihood of stressful events occurring, the appraisal of an event as stressful, and the effectiveness or outcomes of certain coping strategies. ${ }^{27}$ The study by DeLongis and Holtzman ${ }^{41}$ focuses on the Big Five dimensions of personality: neuroticism, extraversion, openness to experience, agreeableness, and conscientiousness. Those that were high on neuroticism were found to be poor at coping, they may choose ineffective strategies that may serve to intensify stressful situations. These personality types reported lower levels of problem solving, and higher levels of confrontation, escape avoidance, and self-blame. Their findings suggest that individuals higher on extraversion appear to be effective and active when it comes to coping in that they are likely to use a variety of coping styles and do it effectively. These personality types were more likely to report engaging in compromise and accepting responsibility. It was also found that higher levels of openness to experience is associated with lower levels of cognitive reframing, and were found to be adaptive, flexible when coping able to engage with others and the world around them. Individuals higher on agreeableness report less confrontation coping and were likely to report engaging in self-blame. High 
conscientiousness individuals are characterized as hard-working and reliable and reported less escape avoidance and self-blame.

Folkman and Lazarus ${ }^{46}$ found that there are four types of coping that were strongly associated with changes in emotion. These were plan-full problem-solving, positive reappraisal, confrontive coping, and distancing. Plan-full problem-solving was associated with an improved emotional state. People can begin to feel better when they turn to the problem that is causing stress. Confrontive coping was associated with worsened emotional states in the younger population. These findings suggest that ones expression of anger and hostility may make them feel worse. Positive reappraisal was associated with improved emotional state in the younger population but not with the older group, who had an increase in distress. Distancing was also a coping style that constantly contributed to a worsened emotional state.

\section{Emotional Responses}

Unfortunately when an athlete gets injured the focus is emphasized on the physical repair and not on the athlete's thoughts, feelings, and behaviors associated with the injury. Any physical impairment that prohibits an athlete from involvement in sport can be cognitively, emotionally, and behaviorally challenging. ${ }^{2}$ Emotional responses begin after a situation is appraised as harmful, beneficial, threatening, or challenging. ${ }^{46}$ The emotions that are generated then influence the type of coping response that is used. The occurrence of an injury may disrupt an athlete's focus and lead to emotional and psychological reactions, which are typically negative.

Athletes often have to deal with some sort of loss in sport participation. Loss has been said to occur across four dimensions: a loss of a significant loved one, the loss of 
some aspect of self, loss of external objects, and developmental loss. ${ }^{2}$ The most common loss experienced through an injury tends to be loss of some aspect of self. ${ }^{2}$ For example, loss of athletic identity or sense of importance on the team can be lost. Athletic identity has been defined as the extent to which an individual relates to the role of being an athlete. ${ }^{47,49}$ Individuals who are involved in athletics and receive encouragement for their participation may focus all of their self-identity to that of being an athlete alone. If someone is centered on the role of an athlete and then becomes injured, his or her selfidentity may be threatened. ${ }^{47}$ An athlete's athletic identity can be strongly influenced by the people that are involved in their social support network.

Green's ${ }^{47}$ study involving 121 injured athletes found a positive significant relationship between athletic identity and measures of depression, with higher athletic identity scores related to more severe depression. Another study by Wiechman ${ }^{49}$, who compared athletic identities among athletes, found that the high school athletes who planned on playing sports in college had a stronger athletic identity. He also noted that males reported higher athletic identities then females.

Athletes respond to the injury experience in very different ways. They are likely to experience multiple and often conflicting emotions. In addition to the physical losses from an injury, there are also decreases in physical conditioning, and changes in lifestyle experienced from the lack of sport participation. ${ }^{2}$ This change in participation leads to a lack of positive experiences obtained through training and competition. Countless athletes feel panic and helplessness when injured. An injury may threaten an athlete's self-concept, self-esteem, belief system, social functioning, values, commitments, and emotional equilibrium. ${ }^{1,2}$ Gayman ${ }^{52}$ noted that injured athletes report negative emotions 
following the onset of a sport injury. Venting of these emotions is the tendency to reflect on whatever distress one is experiencing and to verbalize those feelings in a affect-loaded manner. ${ }^{30}$ Injured athletes may experience anger, frustration, boredom, discouragement, hostility, tension, confusion, fear, anxiety and an inability to concentrate. ${ }^{1,24}$ Among these various feelings, athletes tend to feel isolated and alienated from their teams and their sports. They may feel guilty for getting injured and "letting down" the team, or they may feel ignored by their teammates and coaches.

Research by Johnston ${ }^{21}$ on 16 athletes found that immediately after an injury they are often shocked and are in disbelief of the situation. After the initial shock is when they would appraise the severity of the injury. It wasn't until one week after the injury that the athletes stated feeling anxiety about the circumstances. The athletes also stated that they would feel frustrated and depressed when they were unable to accomplish activities of daily living like they could before the injury. The main trigger of a negative emotional response to an injury was found to be watching others being able to play their sport.

Tracey $^{22}$ interviewed 10 injured male and female athletes at a Division II college about their emotional responses to an injury. All of the athletes reported knowing the risk of getting injured by participating in sport but they were shocked when it actually happened to them. Another common report found was that the visual component of the injury affected their response to the injury. For example, the more bruising and swelling that appeared, the more they worried about the severity of the injury. Also the athletes reported that the most difficult part of recovery was to attending practice and games without being able to participate. They also mentioned that the way they emotionally respond to their injury is highly influenced by how their athletic trainer reacts to it and 
what they say about it. All of the athletes responded saying that they were willing to do whatever it takes to recovery and return to activity.

For an athlete to enhance their emotional well-being, three basic needs should be fulfilled. This falls under the self-determination theory, and to be self-determined the individuals basic needs of competence, autonomy, and relatedness require fulfillment. ${ }^{51,52}$ Competence is the sense that one can effectively bring about desired effects and outcomes. ${ }^{51,52}$ Autonomy is an internal locus of control and the perception that one is the initiator of ones own actions. ${ }^{51,52}$ Relatedness is the personal sense of belonging in the social world, the feeling that one is securely connected to and understood by others. ${ }^{51,52}$ When these three are fulfilled the individual is more likely to experience enhanced social functioning, well-being, and increased intrinsic motivation. ${ }^{51}$ Alienation and acting irresponsible may be possible outcomes if these three needs are ignored. In relation to an athletic injury, competence could be related to the fear of how their body will withstand the demands of the sport, autonomy would be the external pressure they feel to return to play (most athletes value freedom from pressure), and with relatedness the injured athlete might feel alienated from others and needs to feel that belonging again. ${ }^{51}$

One important factor that influences how the athlete will emotionally respond to an injury is the time of season that it occurs. An injury at the beginning of the season may not embrace the same level of negative effects as those in the middle or end of the season. The earlier in the season that the injury occurs, the more optimistic the athlete will be to return to play. ${ }^{21} \mathrm{An}$ injury at the end of the season may be devastating because the athlete may not be able to finish out the season while an injury during post season may be upsetting because the athlete may not be able to start out the beginning of the 
next season. It is also important to remember that not only the time of season but also the extent of the injury determines the intensity of emotions. The athlete's year in school is an individual factor within the time of season that may affect the emotional response. Seniors are more likely to take it harder to be injured during pre-season verses freshmen or sophomores because it could be their last season of play. The end of the season injuries may be more devastating for senior starters because they may feel that they are jeopardizing the teams' ability to succeed. ${ }^{21}$ The end or post season play may be the final opportunity for many seniors to play, so an injury during this time may be devastating to them. The athlete may end up feeling useless and think that they let their team down. It is important to recognize these injured athletes and to see that their emotions are dealt with because they may still play a significant role on the success of the team.

Grieving is an important part of an athletes emotional response to an injury. Grieving is a natural emotional outlet to pain and helps create acceptance of the injury. ${ }^{53}$ There are currently two contemporary models of emotional adjustment developed to better understand how athletes react emotionally to an injury. The two models being explored are the stage models of grief and the cognitive appraisal models of adjustment. Stage models suggest that individuals who experience an injury or illness pass through a predictable series of emotional stages as they recover. ${ }^{47}$

The stages of grief include denial, anger, bargaining, depression, and acceptance. $^{47,53,54}$ First the athlete may deny that the injury occurred or refuse to see how serious the injury is. When the first stage of denial cannot be maintained any longer it is replaced by feelings of anger, which is the next stage in the model. ${ }^{54}$ The next stage is bargaining, which can be seen as an attempt to postpone what is an inevitable outcome. ${ }^{54}$ 
Depression is the next stage that the athlete will go through. The feelings of anger and rage will now be replaced with a sense of great loss, which will lead to depression. ${ }^{54}$ Finally they will accept the reality of the injury and begin focusing on returning to their sport. Acceptance should not be mistaken for a happy stage, it is merely when the athlete realizes what has happened and accepts it. ${ }^{54}$

The basic construction of the cognitive appraisal model is centered on the individual's cognitive assessment of his or her situation (i.e., an injury). ${ }^{47}$ This model explains that how the athlete interprets an injury determines how they will react emotionally. These reactions can range from anger and depression to acceptance of the injury. The fact that the injury occurred is less critical to understanding the emotional reactions than is the way in which the injury is perceived. ${ }^{47}$ The keys to assisting athletes with their grief response is to keep open lines of communication, acceptance of individual emotional responses, and providing unconditional support. ${ }^{53}$

Becoming an elite athlete or evolving into the best athlete you can be at a specific level not only depends on the perfection of biomechanical techniques but to perfect the efficient utilization of cognitive resources. ${ }^{55}$ The way that the athlete interprets and evaluates an injury is known as cognitive appraisal. ${ }^{21}$ This is an important determinant of his or her emotional and/or behavioral response to the injury experience. If the athlete interprets the injury as a threat they are more likely to experience or show negative emotional responses. ${ }^{21}$ If the injury is seen in a somewhat positive way then the athlete believes they will and can cope with the injury and the emotional experience. ${ }^{21}$ Cognitive appraisal is influenced by personal and situational factors. ${ }^{21}$ Personal factors include individual characteristics and personality, self-esteem, and trait anxiety. 
Situational factors are unstable events uncontrollable by the athlete, such as the time of season when the injury occurs. ${ }^{27}$

Once the injury has occurred, the athlete begins the process of cognitive appraisal, which is broken down into primary appraisal and secondary appraisal. ${ }^{38,40,47}$ For the primary appraisal the athlete asks, "Is this harmful to me?”47 Once this assessment is made, the secondary appraisal begins with the question "Will I be able to deal with this situation, and if so, how?" ${ }^{\text {47 }}$ After these questions are answered emotional and behavioral responses to the injury are produced as a result of the appraisal of the situation. ${ }^{47}$ This entire cognitive appraisal model is based on the personal characteristics of the individual and the situational characteristics, including injury and environmental factors. ${ }^{40,47}$ To better understand and treat athletes with an injury, it is better to study these personal and situational characteristics that can influence post-injury reactions.

Anxiety, fear, anger and confusion are just a few of the emotions that an athlete may encounter throughout the injury process. ${ }^{50}$ It is important for the athlete to internalize, accept, and take personal control and responsibility over the injury and recovery. ${ }^{50}$ Athletes cannot avoid their emotions, but there are ways to help them deal with them. Simply allowing the athlete to talk about their feelings regarding the injury is helpful to them. Proper coping skills as well as utilizing the social support network can also help the athlete respond better with their emotional struggles. Psychology of Injury

As many as 750,000 injuries occur each year within collegiate and secondary level athletics alone. ${ }^{47}$ The number of athletic injuries is likely to increase because of societies increasing interest in health and physical fitness. An injury is a traumatic event 
where emotional and psychological reactions occur. An injury often leaves an athlete susceptible to a variety of psychological reactions such as anxiety, depression, fear, and loss of self-esteem. ${ }^{47}$ An injury can lead to changes in how the athlete views him or herself. Ford and Gordon ${ }^{2}$ found that the primary resources lost after knee injury are physical health, finances, mobility/independence, self-perception, achievements, and social roles. Athletes are used to making an impact in a game or sport competition, but being injured may leave them feeling powerless and dependent. ${ }^{24}$ It is normally difficult for athletes to feel vulnerable and trust someone else with their recovery.

Pain is defined as an unpleasant sensory and emotional experience associated with actual or potential tissue damage. More important than the severity of the injury is the athlete's perception of its severity. One should focus on an athlete's verbal description, nonverbal expressions and empathy when assessing the pain they feel from an injury. Certain psychological factors like distraction, relaxation, fear, depression, former pain experiences as well as family and cultural influences alter the way pain is experienced. ${ }^{57}$

Many colligate athletes report the need for counseling in time management, stress, burnout, fear of failure, anxiety, depression, and performance issues. ${ }^{4}$ The majority of the athletic personnel that the athlete faces, such as coaches, teammates, and athletic trainers, are not well trained to recognize signs of this psychological distress. One study by Storch ${ }^{4}$ found that intercollegiate coaches had a significant difficulty recognizing signs of depression in their athletes.

Physical and psychological readiness to return to play after an injury may not be synonymous, but there may be a rise in athletes returning to competition that are physically but not psychologically prepared. The psychological aspect of returning an 
athlete to competition may be difficult due to many factors. The fears about re-injury, concerns about performing up to pre-injury levels, and dealing with feelings of alienation from teammates, coaches, and even oneself are major psychological considerations athletes go through returning to play. ${ }^{51}$ Pressures to return to sport and declines in confidence and performance have also been suggested to exist. ${ }^{51}$

Washington ${ }^{24}$ mentions many cognitive and behavioral strategies involved in the psychology of rehabilitation. One popular strategy is cognitive restructuring, which helps to recognize unproductive thinking patterns and access more productive thoughts. Another one is thought stoppage that helps to recognize negative thoughts and changes them to motivating thoughts. Progressive relaxation and deep breathing were mentioned to be helpful in reducing tension in the body. The last two strategies mentioned are imagery, which helps to mentally practice skills and tasks, and goal setting, assessing both short and long term.

Gould et al. ${ }^{23}$ did a study on the U.S, Ski Team on how to effectively cope psychologically with season ending injuries. Of the 1994-1995 U.S. Ski Team, 41\% had sustained a season-ending injury at some point in their career. There were nine recommendations made by these athletes to enhance coping facilitation. These are: 1) educate and inform; 2) use appropriate motivation; 3) show empathy and support; 4) have a good personality; 5) facilitate positive interactions; 6) customize training for athletes; 7) demonstrate competence and confidence; 8) give athletes confidence; and 9) other. One of the most frequent categories mentioned by the athletes was to educate and inform. There were comments stating, "Tell athletes exactly what happened in surgery,” "Explain how a particular exercise helps,” and “Teach athletes about the body.” Several 
athletes also felt that it would be helpful if sports medicine providers worked more closely with coaches to facilitate a shared understanding between medical providers, coaches, and injured athletes.

A study by Green ${ }^{47}$ investigated the levels of self-esteem in injured and noninjured athletes. One part of the study found that self-esteem was significantly lower in injured runners when compared to those athletes who were able to continue running. Another aspect that compared the injured athletes, athletes that have recovered from an injury and non-injured athletes found that the injured athletes reported significantly lower total and physical self-esteem than the non-injured athletes.

\section{Social Support}

Social support has repeatedly been found to be an important tool for enhancing a patient's psychological recovery. It can act as a specific resource to cover what may be lost or it can help engage underlying resources. There are eight identified categories of social support used commonly in sport. The eight identified are listening support, emotional support, emotional challenge, reality conformation, task appreciation, task challenge, tangible assistance and personal assistance. ${ }^{1,11,12,13}$ Listening support is defined as the perception that another is listening without giving advice or being judgemental. ${ }^{1,11,12,13}$ Emotional support is the perception that another is providing comfort and caring and indicating that he or she is on their side. 1,11,12,13 Emotional challenge is the perception that another is challenging the recipient to evaluate his or her attitudes, values, and feelings. ${ }^{1,11,12,13}$ Reality confirmation is defined as the perception that another, who is similar to and sees things in the same way as the recipient, is helping to confirm their perspective of the world. ${ }^{1,11,12,13}$ Task appreciation is the perception 
that another is acknowledging the recipients efforts and is expressing appreciation for the work he or she does. ${ }^{1,11,12,13}$ Task challenge is described as the perception that another is challenging their way of thinking about a task or an activity in order to motivate to greater creativity, excitement, and involvement. ${ }^{1,11,12,13}$ Tangible assistance is the perception that another is providing them with financial assistance, products, and/or gifts. $1,11,12,13$ The last one is personal assistance and it is defined as the perception that another is providing services or help, such as running errands or driving the recipient somewhere. ${ }^{1,11,12,13}$

Rosenfeld et al. ${ }^{10}$ identified six similar forms of social support, four of which can be giving by any concerned individual and two of which require the provider to have expertise in the technical area relevant to the content of the support offered. The types of support that can be provided by any worried individual are listening support, emotional support, emotional challenge, and shared social reality. Shared social reality refers to others with similar priorities, values, and perspectives. The other two provided by individuals with expertise are technical appreciation and technical challenge. Technical appreciation is to acknowledge when a good piece of work or performance is accomplished and technical challenge is to encourage the athlete to achieve more. In their study ${ }^{10}$ of 170 NCAA Division I athletes, coaches were described as providing technical challenge support primarily and technical appreciation secondarily. Teammates were described as providing technical challenge support primarily and listening and shared social reality support secondarily. They found that the athletes friends were described as providing listening and shared social reality primarily and emotional support secondarily. Parents were found to provide technical appreciation support and emotional 
support primarily and listening support secondarily. Coaches were not listed to provide any listening, emotional, or shared social reality support. Coaches avoid these support styles for one to sustain their role as an authority figure and to avoid affecting morale by singling out certain athletes to share a more personal or supportive relationship.

An article by Ford ${ }^{2}$ identified similar types of social support. Those types are encouragement, reassurance, advice, maintaining involvement, personal assistance, and financial assistance. These six types of social support were acknowledged and identified by the athletes that participated in the study. These behaviors helped them to cope more effectively with the stress they encountered from the threatened resources resulting from injury.

A study by $\mathrm{Udry}^{58}$ identified four types of social support that was relevant to their research. These four are esteem/emotional support, tangible support, informational support, and motivational support. Some examples of esteem/emotional social support are reassuring behaviors, communicating acceptance and love, and showing empathy and affection. Tangible support is providing assistance or goods, like transportation or fixing meals. Informational social support is advice given that is targeted at problem solving or feedback. The components of motivational support include providing encouragement to overcome obstacles. Using these four categories, esteem/emotional support occurred $41 \%$ of the time in the rehabilitation of injured athletes, with motivational used $24 \%$ of the time, informational $23 \%$ of the time, and tangible support used the least at $12 \%$ of the time.

Social support involves a network of personal ties that serve to meet the need of the individual by reducing uncertainty during times of stress, providing companionship, 
and aiding in mental and physical recovery. ${ }^{10,11,18,59}$ The presence of an appropriate social support system is positively related to improved recovery in rehabilitation and decreased stress. ${ }^{10,11,38,59}$ Greater satisfaction with ones own support leads to greater use of adaptive ways of coping with stressful situations. Social support systems usually include teammates, coaches, team physicians, athletic trainers, sport psychologist, family, and friends. ${ }^{1,10,11,24}$ Support from others is viewed as a system of enduring interpersonal ties to those who can be relied on to provide emotional nourishment and resources in times of need as well as provide feedback according to shared standards and values. ${ }^{29}$ Social support is effective in enhancing well-being because it acts as coping assistance. People turn to others for a sense of what is considered "right” in certain situations. Attentiveness, respect, and empathy must be the most common attributes that anyone in a social support network must provide. ${ }^{60}$

In most situations, social support is intended to be helpful but there are often attempts to support that are not perceived as helpful by the recipient. This disappointment may stem from a perceived lack of support, a failure of support attempts to meet the needs of the recipient, or un-intended interactions with support providers, such as criticism or avoidance. ${ }^{19,41}$ Absence or negative social support may be viewed as a stressor itself which can lead to isolation and frustration. ${ }^{18}$ One reason that an individual may not feel that they are receiving the appropriate type or amount of social support is that they may distance themselves from their own pain and in turn will not provide the right cues to their social network that they are in pain and in need of support. If potential support providers do not receive the cues indicating the need for support, they 
may fail to provide that needed support. A lack of social support is seen as a stumbling block in recovering emotionally from an injury. ${ }^{50}$

Social support has been defined as "an exchange of resources between as least two individuals perceived by the provider or the recipient to be intended to enhance the well-being of the recipient."10,12,24,61 Another definition used is “information from others that one is loved and cared for, esteemed and valued, and part of a network of communication and mutual obligations.”12 One way that an athletic trainer can enhance their athlete’s psychological recovery from an injury is through providing social support. However, offering social support may be simple at times, it can also become quite complex. Athletes expect, and need, to receive social support not only from certified athletic trainers and coaches, but from their peers as well.

Social support is not only important to enhance injury rehabilitation, but it also influences and enhances the overall athletic experience. Social support is multidimensional that involves emotional and informational support that is related to decreased levels of overall life stress and a decreased incidence of athletic injury. ${ }^{8,24,29}$ It can also affect the athlete's motivation, commitment, and the ability to overcome adversity. ${ }^{17}$ Social support buffers or reduces the negative health outcomes associated with stress. The type, number, and providers of social support may influence the extent to which athletes find sport stressful and also their responses to the demands of the sport. ${ }^{8}$

A study ${ }^{62}$ on six male athletes who sustained spinal cord injuries were interviewed by Rees ${ }^{62}$ on their perceptions of social support. He based his questions on the 4demensional model of social support, which are emotional support, esteem support, informational support, and tangible support. One of the findings suggested that there was 
a difference in support received while they were in the hospital when compared to moving back home. They mentioned that their needs were constantly catered at the hospital and once they were at home again there was not as many people to take care of them and they felt more isolated. The most common type of emotional support received was having others simply being there for them. The esteem support they mainly received was encouragement and reassurance. Informational support was provided by others offering ways to deal with their feelings of anger and frustration and tangible assistance was perceived as the physical therapy that they had received. All six athletes regard social support as very important and that it is a critical part of their being able to increase their quality of life.

Athletic trainers: The injured athletes first and most frequent point of contact within the health care system is the athletic trainer. ${ }^{12}$ Injured athletes often see athletic trainers on a daily basis from the time they are injured until the time he or she returns to competition. The athlete and the athletic trainer spend countless hours working together, especially after an injury. Athletic trainers do see athletes often and they have the power to sideline the athlete. However, their main responsibility involves detecting, diagnosing, and rehabilitating injured athletes to return to play as fast and as safe as possible. This significant relationship puts the athletic trainer in a position to affect the athlete's psychological recovery from injury, in addition to the physical healing. An athletic trainer needs to listen to the athlete and also provide educational aspects of the injury and develop a rehabilitation protocol. Education of the injury and rehabilitation gives the athlete a greater sense of control. One important role of an athletic trainer is to play a 
role of a counselor facilitating the physical and emotional transition the athlete will undergo during an injury. ${ }^{53}$

An article by Bone and Fry ${ }^{11}$ found that their Division I athletes reported listening support as the most important type of social support. The athletes also perceived that their certified athletic trainer played an important role in their social support network because they engaged them in challenging rehabilitation exercises. The harder the challenge of an exercise the more belief they had in rehabilitation. The athletes also felt that treatment was more effective when they perceived that the athletic trainer was providing some sort of tangible assistance, like bracing, taping, or setting up a doctor's appointment. The athletes reported that they felt they were able to adhere better to rehabilitation when the athletic trainer demonstrated alliance and confirmed their progress. When comparing the severity of injuries there was no significant difference between athletes with severe verses mild to moderate injuries with regard to the social support they perceived they received from their athletic trainer.

Current reports show that athletes, on average, may experience more psychological problems then their non-athlete peers. ${ }^{4}$ It is important to keep in mind that the athletes needs go beyond physical care. They need to know that there are people who understand the frustration they are experiencing, the physical pain their injuries are causing, and the emptiness they are feeling from not being able to do what they love. ${ }^{12}$ It is wrong to assume that someone else will be providing them with the needed support or to think that the athlete already understands that he or she is cared for. Athletes, in particular, need athletic trainers to take the time to listen to them. Most importantly, injured athletes need to know that the exercises and work they accomplish as part of their 
rehabilitation are appreciated. ${ }^{12}$ This need for social support is high during the injury period as is the need to know that others understand what they are going through. ${ }^{12}$ Most athletes have the need and want to be pushed to succeed in their rehabilitation, just as they would in their sports.

It is also an important role of the athletic trainer to educate others who may be in the athlete's social support system. Athletic trainers should discuss the primary psychosocial effects of the injury with the coaching staff. Athletic trainers play the mediating role between athletes and coaches, and they need to use this position to explain to coaches what they should do with their injured athletes. Along with this, they should show them how to encourage their injured athletes and how they should support them through this process. It is important to know that the psychological process is unique to each athlete, each individual will respond different to similar injuries.

A study by Washington ${ }^{24}$ found that $45.7 \%$ of the athletic trainers that participated and completed a questionnaire reported that they could assist in the psychological recovery in a limited capacity. When asked whether they were comfortable with the knowledge they had on the psychological aspects of rehabilitation, $68 \%$ responded that they were. Another important finding was that $61 \%$ of the athletic trainers that responded to the questionnaire think it is important to involve the athlete in decision making and $79 \%$ of them say they involve them almost always. Of the athletic trainers that responded to Washington's questionnaire, 33.3\% reported that they, at some point, were in a situation where they knew what should be done, but either didn't know how to do it or did not have the confidence to do it. Athletes adhere better to the 
rehabilitation protocol when they feel that the healthcare professionals are interested in their well-being.

Coaches: The coaches play a very important role in the athlete's lives. Coaches constantly provide feedback and reinforcement about performance that the athlete may use to correct, motivate, and reinforce their skills and behaviors. ${ }^{42}$ Many athletes spend more time with teammates and coaches then they do with their peers or even their own families. It is often pondered why coaches do not choose to provide the right kind of social support when their athletes get injured. Most often coaches claim that it was inappropriate, that the players need to figure out on the problem on their own, or that it was unfair to the remainder of the team. ${ }^{1}$ Injured athletes are more likely to view their coaches role as primarily negative during their recovery. ${ }^{18}$ Rather than assisting the injured athletes, coaches tend to ignore them, neglect to console them, and instead of encouraging their rehabilitation, merely question when they will return. ${ }^{1}$

If coaches provide poor social support the athlete may develop a negative attitude toward the coach, decreased competence, increased anxiety, and decreased motivation. ${ }^{42}$ It is important for coaches to stay positive, emphasize hard work, and show care and compassion in and out of the sporting arena. Athletes often see their coaches as providing negative influence. The negative support can be viewed as providing pressure, having unrealistic expectations, having conflicting ideas, or not showing belief. ${ }^{18}$

Coaches are perceived as providing task challenge, task appreciation, and emotional challenge support, and are perceived as specifically not providing reality conformation support, listening support, and emotional support. ${ }^{1,50}$ Head and assistant coaches have the responsibility to mandate who will play and who will sit on the bench 
on any given day. These individuals have the authority to control the direction of the athlete’s career. Coaches also see the athletes everyday at practice and are given more then an opportunity to encourage an injured athlete. This encouragement is a type of support that could possibly enhance their self-esteem and ability to cope with the injury. ${ }^{1}$ If the coaches choose to ignore the injured athlete it could add to his or her feelings of frustration and possibly discourage a positive recovery. ${ }^{1}$

There are various ways that coaches can improve their support of their athletes. The coaches can start by putting him or her into stationary positions in drills and assign various duties that would not harm him or her or risk further injury. By involving athletes, they may feel more appreciated and noticed, and feel less isolated from the team or frustrated with their situation. Another important way that coaches can be supportive is by being involved in the athletes rehabilitation by visiting the athletic training room at least once a week and check up on the athlete, rather than hearing about their progress from the athletic trainers. In addition, social support from coaches during rehabilitation helps maintain their relationship with the athletes. This support will also help to avoid any awkwardness upon the injured athlete's return to play. Coaches should create an environment that will enable athletes to express their feelings, concerns and fears without judgment from others.

Coaches should always be providing performance encouragement, individual instruction, active listening and develop team cohesion. ${ }^{31}$ Ryska ${ }^{31}$ researched 270 athletes about their perceived support from coaches. He found that perceived coach support significantly influenced the competitive anxiety levels of high school tennis 
athletes. For example, the high-trait anxious athletes who reported high levels of coach support showed lower pre-competitive state anxiety.

A study by Robbins and Rosenfeld ${ }^{1}$ on 35 Division 1 athletes found that they felt assistant coaches provided more task challenge pre-injury then during their time spent in rehabilitation. During interviews with these athletes, the respondents suggested that assistant coaches see their role as technical advisors, to attend practice and teach skills. If an athlete is injured and is not participating in practice, they have no reason to provide task challenge support. The athletes in this study responded that they were more satisfied with the support that they received from the athletic trainers then from their coaches or assistant coaches. Injured athletes perceived that their athletic trainers' listening, task appreciation, task challenge, and emotional challenge report as more influential to their well-being than support from either their head or assistant coaches. All of the athletes that served as respondents mentioned that more support from the coaching staff would have been readily accepted and appreciated.

Family, friends, and teammates: The parent's role in providing social support has great influence on the athlete early on in their athletic career. When the athlete first starts out in sport the parents provide support by always being there, providing rides to and from practice and games, and are more available to attend their performances. ${ }^{17,45}$ Later on in the athletes collegiate career their support becomes more indirect. With the child living away from home they can only communicate with phone calls and are unable to see their child as much. It is also harder for them to travel and see them play most of their games. The nature and importance of social support often changes and evolves as the athlete grows older. The type of support given by the family is emotional support. ${ }^{17,18}$ 
The knowledge that their family is always there for them and provides unconditional support is very important to the athlete. Another common type of support provided is tangible assistance. ${ }^{17,18}$ Families provide this type of support by aiding in the athletes finances and material needs.

Both family and friends are an important source of social support because they are the ones who may have introduced them into sport, supported them throughout, and encouraged their involvement. An athlete's family and peers exert a considerable amount of influence on their sport involvement and behavior. More importantly the family and friends become socializing agents for young athletes into sport. ${ }^{45}$ Parents can provide a positive influence by demonstrating supportive behaviors and provide a low stress environment. ${ }^{18}$

In college their teammates may take on a more important role in the social support network when compared to their family and friends. Athletes constantly learn from their team, both in sport and out of sport. Teammates can make each others life easier because they understand what the other is going through and allow them to stay grounded. The team gives each athlete someone that they can identify with and share their common experiences. ${ }^{17,19}$ An athlete's teammates provide emotional support by serving as a constant challenge to their emotional state. ${ }^{18,50}$ The team can also provide a sense of understanding, motivation, and also offer some form of tangible assistance. ${ }^{18}$ Social support from a teammate can also maintain a sense of connection to their sport and team..$^{50}$ 
Summary

Being injured is something that athletes cannot avoid. What are often not confronted are the other effects that an injury may have on an athlete besides the physical outcomes. The psychological aspects of injury rehabilitation can be a troubling experience for many athletes. Being injured can be a very stressful situation and it is important for the athlete to know that they are not alone. Athletic trainers involved in an athlete's life should be able to recognize the stress that stems from sport participation, the emotions that they can go through, and the psychological process that is followed after an injury may occur.

Any stress that an athlete may experience in their athletic career can lead to decreased motivation, emotional distress, poor athletic performance, increase risk of injury, and eventually psychological burnout and withdrawal from competitive sport. ${ }^{5,6,7}$ Coping successfully in sport when faced with stress can help the athlete gain composure and maintain concentration. An athlete's social support system is a significant factor in physical and psychological recovery from an injury. The athlete's perception of the type of support that is provided is also important so they know who will provide the care when necessary. Social support can positively affect the healthy outcome of an athlete and everyone involved in an athlete's social support system needs to be aware of their role and its importance to the athlete. 
APPENDIX C

ADDITIONAL METHODS

Table C1: Demographic Questionnaire.

\section{Demographic Questionnaire}

Subject Number:

Hometown/State:

Sport:

Year in school when injured: Freshman Sophomore Junior Senior

Year on the team when injured: $1^{\text {st }} \quad 2^{\text {nd }} \quad 3^{\text {rd }} \quad 4^{\text {th }} \quad 5^{\text {th }}$

Rank when injured: Starter Substitute

Injury:

Will you require surgery? YES NO

Will it be a season ending injury? YES NO

If no, how long will you be out? weeks

When did the injury occur? PRACTICE GAME

FALL SPRING 


\section{Social Support Questionnaire}

Subject Number:

The following questions focus on individuals in your environment who have provided you with help and/or support for you most recent injury and rehabilitation. Read the definition of the type of support being considered and respond to the questions that follow it. Please answer ALL the questions as best you can-there are no right or wrong answers. All of your responses are strictly confidential.

\section{Listening Support - People who listen without giving advice or being judgmental.}

Rate your satisfaction with the overall quality of the listening support you received.

$\begin{array}{ccccc}1 & 2 & 3 & 4 & 5 \\ \text { very dissatisfied } & \text { dissatisfied } & \text { indifferent } & \text { satisfied } & \text { very satisfied }\end{array}$

How difficult would it be for you to obtain more listening support?

$\begin{array}{ccccc}1 & 2 & 3 & 4 & 5 \\ \text { very difficult } & \text { difficult } & \text { indifferent } & \text { easy } & \text { very easy }\end{array}$

How important is it for you to have one or more people provide you with listening support?

$\begin{array}{ccccc}1 & 2 & 3 & 4 & 5 \\ \text { not important } & \text { somewhat important } & \text { indifferent } & \text { important } & \text { very important }\end{array}$

Who provided you with listening support (please rank in order starting with those who provided the most to those who provided the least)

$\begin{array}{ll}\text { Athletic Trainers/Physicians } & \text { Family } \\ \text { Coaches } & \text { Friends } \\ \text { Teammates } & \text { Others (please list) }\end{array}$

Emotional Support - People who provide comfort and caring and indicate that they are on your side.

Rate your satisfaction with the overall quality of the emotional support you received.

$\begin{array}{ccccc}1 & 2 & 3 & 4 & 5 \\ \text { very dissatisfied } & \text { dissatisfied } & \text { indifferent } & \text { satisfied } & \text { very satisfied }\end{array}$

How difficult would it be for you to obtain more emotional support?
1
very difficult
2
3
indifferent
4
easy 
How important is it for you to have one or more people provide you with emotional support?

$\begin{array}{ccccc}1 & 2 & 3 & 4 & 5 \\ \text { not important } & \text { somewhat important } & \text { indifferent } & \text { important } & \text { very important }\end{array}$

Who provided you with emotional support (please rank in order starting with those who provided the most to those who provided the least)

Athletic Trainers/Physicians Coaches Teammates
Family

Friends

Others (please list)

Emotional Challenge - People who challenge you to evaluate your attitudes, values, and feelings.

Rate your satisfaction with the overall quality of the emotional challenge you received.

$$
\begin{array}{ccccc}
1 & 2 & 3 & 4 & 5 \\
\text { very dissatisfied } & \text { dissatisfied } & \text { indifferent } & \text { satisfied } & \text { very satisfied }
\end{array}
$$

How difficult would it be for you to obtain more emotional challenge?

$\begin{array}{ccccc}1 & 2 & 3 & 4 & 5 \\ \text { very difficult } & \text { difficult } & \text { indifferent } & \text { easy } & \text { very easy }\end{array}$

How important is it for you to have one or more people provide you with emotional challege?

$\begin{array}{ccccc}1 & 2 & 3 & 4 & 5 \\ \text { not important } & \text { somewhat important } & \text { indifferent } & \text { important } & \text { very important }\end{array}$

Who provided you with emotional challenge (please rank in order starting with those who provided the most to those who provided the least)

$\begin{array}{ll}\text { Athletic Trainers/Physicians } & \text { Family } \\ \text { Coaches } & \text { Friends } \\ \text { Teammates } & \text { Others (please list) }\end{array}$

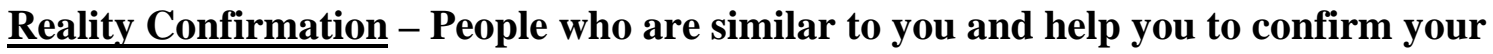 perceptions and perspectives of the world and keep your focus.}

Rate your satisfaction with the overall quality of the reality confirmation you received.

$\begin{array}{ccccc}1 & 2 & 3 & 4 & 5 \\ \text { very dissatisfied } & \text { dissatisfied } & \text { indifferent } & \text { satisfied } & \text { very satisfied }\end{array}$

How difficult would it be for you to obtain more reality confirmation?

$\begin{array}{ccccc}1 & 2 & 3 & 4 & 5 \\ \text { very difficult } & \text { difficult } & \text { indifferent } & \text { easy } & \text { very easy }\end{array}$


How important is it for you to have one or more people provide you with reality confirmation?

$\begin{array}{ccccc}1 & 2 & 3 & 4 & 5 \\ \text { not important } & \text { somewhat important } & \text { indifferent } & \text { important } & \text { very important }\end{array}$

Who provided you with reality confirmation (please rank in order starting with those who provided the most to those who provided the least)

Athletic Trainers/Physicians

Coaches

Teammates
Family

Friends

Others (please list)

\section{Task Appreciation - People who acknowledge and express appreciation for what} you do.

Rate your satisfaction with the overall quality of the task appreciation you received.

$\begin{array}{ccccc}1 & 2 & 3 & 4 & 5 \\ \text { very dissatisfied } & \text { dissatisfied } & \text { indifferent } & \text { satisfied } & \text { very satisfied }\end{array}$

How difficult would it be for you to obtain more task appreciation?

$\begin{array}{ccccc}1 & 2 & 3 & 4 & 5 \\ \text { very difficult } & \text { difficult } & \text { indifferent } & \text { easy } & \text { very easy }\end{array}$

How important is it for you to have one or more people provide you with task appreciation?

$\begin{array}{ccccc}1 & 2 & 3 & 4 & 5 \\ \text { not important } & \text { somewhat important } & \text { indifferent } & \text { important } & \text { very important }\end{array}$

Who provided you with task appreciation (please rank in order starting with those who provided the most to those who provided the least)

Athletic Trainers/Physicians Coaches

Teammates
Family

Friends

Others (please list)

\section{Task Challenge - People who challenge your way of thinking in order to motivate} you.

Rate your satisfaction with the overall quality of the task challenge you received.

$$
\begin{array}{ccccc}
1 & 2 & 3 & 4 & 5 \\
\text { very dissatisfied } & \text { dissatisfied } & \text { indifferent } & \text { satisfied } & \text { very satisfied }
\end{array}
$$

How difficult would it be for you to obtain more task challenge?

$$
\begin{array}{ccccc}
1 & 2 & 3 & 4 & 5 \\
\text { very difficult } & \text { difficult } & \text { indifferent } & \text { easy } & \text { very easy }
\end{array}
$$


How important is it for you to have one or more people provide you with task challenge?

$$
\begin{array}{ccccc}
1 & 2 & 3 & 4 & 5 \\
\text { important } & \text { somewhat important } & \text { indifferent } & \text { important } & \text { very important }
\end{array}
$$

Who provided you with task challenge (please rank in order starting with those who provided the most to those who provided the least)

Athletic Trainers/Physicians Coaches Teammates
Family

Friends

Others (please list)

Tangible Assistance - People who provide you with financial assistance, products, or gifts.

(this does NOT include scholarship money, sponsorships, or recruitment gifts)

Rate your satisfaction with the overall quality of the tangible assistance you received.

$\begin{array}{ccccc}1 & 2 & 3 & 4 & 5 \\ \text { very dissatisfied } & \text { dissatisfied } & \text { indifferent } & \text { satisfied } & \text { very satisfied }\end{array}$

How difficult would it be for you to obtain more tangible assistance?

$\begin{array}{ccccc}1 & 2 & 3 & 4 & 5 \\ \text { very difficult } & \text { difficult } & \text { indifferent } & \text { easy } & \text { very easy }\end{array}$

How important is it for you to have one or more people provide you with tangible assistance?

$$
\begin{array}{ccccc}
1 & 2 & 3 & 4 & 5 \\
\text { not important } & \text { somewhat important } & \text { indifferent } & \text { important } & \text { very important }
\end{array}
$$

Who provided you with tangible assistance (please rank in order starting with those who provided the most to those who provided the least)

$\begin{array}{ll}\text { Athletic Trainers/Physicians } & \text { Family } \\ \text { Coaches } & \text { Friends } \\ \text { Teammates } & \text { Others (please list) }\end{array}$

\section{Personal Assistance - People who provide services such as running errands or driving you somewhere.}

Rate your satisfaction with the overall quality of the personal assistance you received.

$\begin{array}{ccccc}1 & 2 & 3 & 4 & 5 \\ \text { very dissatisfied } & \text { dissatisfied } & \text { indifferent } & \text { satisfied } & \text { very satisfied }\end{array}$

How difficult would it be for you to obtain more personal assistance?

$\begin{array}{ccccc}1 & 2 & 3 & 4 & 5 \\ \text { very difficult } & \text { difficult } & \text { indifferent } & \text { easy } & \text { very easy }\end{array}$


How important is it for you to have one or more people provide you with personal assistance?

$\begin{array}{ccccc}1 & 2 & 3 & 4 & 5 \\ \text { not important } & \text { somewhat important } & \text { indifferent } & \text { important } & \text { very important }\end{array}$

Who provided you with personal assistance (please rank in order starting with those who provided the most to those who provided the least)

Athletic Trainers/Physicians Coaches Teammates
Family

Friends

Others (please list)

Please rank the types of support in order from most important (1) to least important (8):

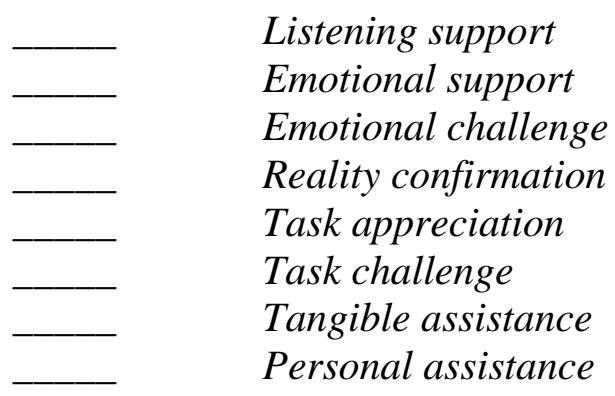

Please list the two most important people (or groups of people) who provided support throughout your injury process (athletic trainers, coaches, teammates, family, friends, etc.): 


\section{Interview Questions}

1. Tell me about your experience coping with this injury.

2. What have you had to deal with that is different or challenging with this injury?

3. Social support is the presence of others whom you can rely on and know that they value and care for your well-being. How satisfied are you with the social support that you have received from being injured?

4. Tell me a little about how other people have helped you cope with your injury.

5. Who are three people whom you perceive to have provided you with the most support while you are injured? (the following questions will be asked if not enough information was provided with the initial question)

a. How did your coach contribute, whether it be helpful or not, during your injury process?

b. How did your certified athletic trainer contribute during your injury process?

6. Tell me how and what could have made your injury rehabilitation process easier and smoother.

7. What else do you feel you needed to help you cope with your injury?

a. Where did you get this?

8. Tell me about any emotional and listening support you have received.

a. Who provided it?

9. Tell me about any financial or personal assistance you have received while being injured.

a. Who provided it?

10. Tell me about your experience with receiving any task challenge or task appreciation throughout your injury process.

a. Who provided it 
Table C4: Consent and Information Form

CONSENT AND INFORMATION FORM

PERCEIVED SOCIAL SUPPORT SYSTEMS DURING ATHLETIC INJURY RECOVERY IN COLLEGIATE CLUB SPORT ATHLETES

\section{Introduction}

I, , have been asked to participate in this research study which has been explained to me by Jacque Loutsch, ATC. She is conducting this research under the supervision of Michelle A. Sandrey, PhD, ATC in partial fulfillment of the requirements for the completion of a thesis and the Master of Science degree in Athletic Training in the School of Physical Education at West Virginia University.

\section{Purpose of the Study}

The purpose of this study is to determine the perceived social support systems used after an athletic injury and who provides each type of support. It will also investigate if there is a difference in support received between club sport athletes. West Virginia University expects to enroll approximately 10 subjects.

\section{Description of Procedures}

This study involves completing a questionnaire that will ask me questions regarding my social support systems. The questionnaire examines the types of support each athlete receives and who provides the support. The questions are similar for each type of support-emotional, listening, personal assistance, tangible assistance, emotional challenge, task challenge. The enclosed questionnaire consists of 32 social support questions and a demographic questionnaire. The social support questionnaire uses a fivepoint Likert scale to measure satisfaction of support, ease of obtaining support, and importance of support. The questionnaire will take approximately 20 minutes to complete. I understand that I do not have to answer all of the questions if I decide to participate. I will also participate in an audio taped interview about my perceived social support system. The questions will be taken from the social support survey that I will have completed. The interview will take approximately 20 minutes to complete.

Submission Date $\underline{\text { 3-7-07 }}$

Page 1 of 3

$\overline{\text { Initials }} \quad \overline{\text { Date }}$




\section{PERCEIVED SOCIAL SUPPORT SYSTEMS DURING ATHLETIC INJURY RECOVERY IN COLLEGIATE CLUB SPORT ATHLETES}

\section{Risks and Discomforts}

There are no known risks from participation in this study except for the fear of being identified. However, all questionnaires will be coded to maintain confidentiality.

\section{Alternative}

I understand that I do not have to participate in this study, and that I can stop my participation in this study at any time. No negative actions will be taken against me if I choose not to participate.

\section{Benefits}

I understand that this study is not expected to be of direct benefit to me, but the knowledge gained may be of benefit to others.

\section{Financial Considerations}

I understand that I will receive no monetary compensation for completing this study.

\section{Confidentiality}

I understand that any information about me obtained as a result of my participation in this research will be kept as confidential as legally possible. Identifying information on the informed consent form and social support questionnaire/demographic history questionnaire and audiotapes from the interview will be kept confidential by assigning a code number to each informed consent form and questionnaire as well as audiotapes. The questionnaires will be kept in a concealed envelope and the audiotapes will be locked up when not being used for data. In any publications that result from this research, neither my name nor any information from which I might be identified will be published without my consent.

Page 2 of 3

Submission Date 3-7-07

\section{Initials Date}




\section{PERCEIVED SOCIAL SUPPORT SYSTEMS DURING ATHLETIC INJURY RECOVERY IN COLLEGIATE CLUB SPORT ATHLETES}

\section{Voluntary Participation}

Participation in this study is voluntary. I understand that I am free to withdraw my consent to participate in this study at any time and that such refusal to participate will not affect my future care, class standing or grades, or position on the team. Refusal to participate or withdraw will involve no penalty to me. I have been given the opportunity to ask questions about the research, and I have received answers concerning areas I did not understand. In the event new information becomes available that may affect my willingness to continue to participate in this study, this information will be given to me so I may make an informed decision about my participation.

Upon signing this form I will receive a copy.

I willingly consent to participate in this research.

Signature of Subject

Date/Time

The participant has had the opportunity to have questions addressed. The participant willingly agrees to be in the study.

Signature of Investigator or Co-Investigator

Date/Time

Printed Name

Date/Time

\section{Contact Persons}

For more information about this research, I can contact Jacque Loutsch, ATC at (712) 540-7820 or jloutsch@mix.wvu.edu, or Dr. Michelle A. Sandrey at (304) 293-5220 ext 5220 or msandrey@mail.wvu.edu. For information regarding my rights as a research subject, I may contact the Executive Secretary of the Institutional Review Board of West Virginia University at (304) 293-7073.

Page 3 of 3

Submission Date $\underline{\text { 3-7-07 }}$

$\overline{\text { Initials }} \quad$ Date 


\section{Authorization to Use or Disclose Protected Health Information (PHI)}

\section{West Virginia University}

I hereby voluntarily authorize the use or disclosure of my individually identifiable health information as described below.

Patient Name:

Date of Birth:
ID Number:

IRB Protocol \#:

Persons/organizations providing the protected health information (e.g. hospitals):

West Virginia University Athletic Training, and HealthWorks Rehab and Fitness.

Persons/organizations receiving the information (e.g. investigators, clinical coordinators, sponsor, FDA):

Jacque Loutsch, ATC.

The following information will be used:

Any medical records pertaining to the injury.

The information is being disclosed for the following purposes (Start with the Title of the study and include additional information e.g. screening and recruiting subjects; analyzing research data, or other specified purposes):

Perceived Social Support Systems During Athletic Injury Recovery in Collegiate Club Sport Athletes; Demographic information and social support questionnaire.

I may revoke this authorization at any time by notifying the Principal Investigator in writing at:

$\begin{array}{ll}\text { (Name and address of PI) } & \text { Jacque Loutsch } \\ & \text { Graduate Assistant Athletic Trainer } \\ & \text { PO Box 6116 } \\ & \text { Morgantown, WV 26506-6116 }\end{array}$

If I do revoke my authorization, any information previously disclosed cannot be withdrawn. Once information about me is disclosed in accordance with this authorization, the recipient may redisclose it and the information may no longer be 
protected by federal privacy regulations.

\section{Authorization to Use or Disclose Protected Health Information (Contd.)}

I may refuse to sign this authorization form. My clinical treatment may not be affected by whether or not I sign this form. I may not be allowed to participate in the research if I do not sign the form.

This authorization will expire on the date that the research study ends. (Other options for expiration include an actual date of expiration, occurrence of a particular event, or "none" if the authorization will have no expiration date.)

Expiration date:

I will be given a copy of this authorization form.

Signature of subject or subject's legal representative

Date

(Form MUST be completed before signing)

Printed name of subject's legal representative
Relationship to the subject
\begin{tabular}{|l}
\hline \\
Parent \\
Medical power of attorney/representative \\
Legal guardian \\
Health care surrogate
\end{tabular}

Initials

Page 2 of 2 


\section{Table C6: Cover Letter}

March 7, 2007

Dear Club Sport Athlete:

I am conducting research on the perceived social support systems of club sport athletes after injury. The purpose of this study is to determine which types of social support systems are uses and who provides the different types of support. A secondary purpose is to investigate the types of social support that are perceived to be most important. The research is being conducted to partially fulfill the requirements for a thesis and the completion of the Master of Science degree in Athletic Training at West Virginia University.

The following questionnaire includes several demographic questions and 32 multiple choice/ranking questions regarding the support you received after your injury. The battery of questions should take approximately 20 minutes to complete. Please answer the questions to the best of your ability. A week after completing the questionnaire there will be an audio recorded interview based on the social support questionnaire. The interview should take approximately 20 minutes to complete.

Coding will be used to keep track of your responses. Your name will not be associated with your response. I will be the only person with access to the information you provide. Your responses will remain anonymous and confidential. Participation in this study is completely voluntary and you are not required to answer every question. Your grades, position on the team, and treatment will not be affected by refusing to participate. You have the right to withdraw any data you submit at any time. Completing and returning this questionnaire will serve as your consent to participate. If you do choose to participate, please complete the questionnaire and place it in the provided folder when finished.

If you have questions or concerns, please feel free to contact me, Jacque Loutsch, at 712-5407820 or jloutsch@mix.wvu.edu. You may also contact my supervisor, Dr. Michelle Sandrey at 304-293-3295 x5220 or msandrey@mail.wvu.edu with any questions regarding this research.

Thank you for you participation,

Sincerely,

Jacque Loutsch, ATC

* This study will be approved by the Institutional Review Board (IRB) for the protection of human subjects at West Virginia University and the School of Physical Education. 
APPENDIX D

$\underline{\text { ADDITIONAL RESULTS }}$

Table D1: Demographic Information

\begin{tabular}{|c|c|c|c|c|c|c|c|c|c|c|c|}
\hline & Age & Gender & Sport & State & Yr in school & Rank & Injury & Surgery & $\begin{array}{l}\text { Season } \\
\text { ending }\end{array}$ & $\begin{array}{c}\text { Wks } \\
\text { out }\end{array}$ & $\begin{array}{l}\text { When } \\
\text { occured }\end{array}$ \\
\hline Subject 1 & 22 & female & rugby & PA & junior & starter & ACL sprain & no & no & 6-8 wks & practice \\
\hline Subject 2 & 23 & male & rugby & VA & senior & starter & AC sprain & no & no & 3-4 wks & game \\
\hline Subject 3 & 19 & male & hockey & PA & freshman & substitute & AC sprain & no & no & 3 wks & game \\
\hline Subject 4 & 22 & male & rugby & $\mathrm{DE}$ & senior & starter & displaced teeth & no & no & 2-3 wks & game \\
\hline Subject 5 & 22 & male & hockey & PA & junior & substitute & patella tracking & g no & yes & & practice \\
\hline Subject 6 & 20 & female & rugby & WV & sophomore & starter & shin splints & no & no & 3 wks & practice \\
\hline Subject 7 & 21 & female & rugby & WV & junior & starter & ACL sprain & no & no & 2 wks & game \\
\hline
\end{tabular}


Table D2: Frequencies for Year in School

\begin{tabular}{lcc} 
Rank & Frequency & Percent \\
\hline Freshman & 1 & $14.3 \%$ \\
Sophomore & 1 & $14.3 \%$ \\
Junior & 3 & $42.9 \%$ \\
Senior & 2 & $28.6 \%$ \\
\hline
\end{tabular}

Table D3: Frequencies for Gender

\begin{tabular}{lcc} 
Gender & Frequency & Percent \\
\hline Male & 4 & $57.1 \%$ \\
Female & 3 & $42.9 \%$ \\
\hline
\end{tabular}

Table D4: Frequencies for When Injured

\begin{tabular}{lcc} 
When injured & Frequency & Percent \\
\hline Spring Game & 4 & $57.1 \%$
\end{tabular}

$\begin{array}{lll}\text { Spring Practice } & 3 & 42.9 \%\end{array}$


Table D5: Frequency of Responses to Satisfaction with the Quality of Support

\begin{tabular}{lccccc}
\hline Type of Support & Very Dissatisfied & Dissatisfied & Indifferent & Satisfied & Very Satisfied \\
Listening & 0 & 0 & 0 & $1(14.3 \%)$ & $6(85.7 \%)$ \\
Emotional & 0 & 0 & 0 & $2(28.6 \%)$ & $5(71.4 \%)$ \\
Emotional Challenge & 0 & 0 & $1(14.3 \%)$ & $4(57.1 \%)$ & $2(28.6 \%)$ \\
Reality Confirmation & 0 & 0 & $2(28.6 \%)$ & $4(57.1 \%)$ & $1(14.3 \%)$ \\
Task Appreciation & $1(14.3 \%)$ & 0 & $1(14.3 \%)$ & $4(57.1 \%)$ & $1(14.3 \%)$ \\
Task Challenge & 0 & 0 & $2(28.6 \%)$ & $3(42.8 \%)$ & $2(28.6 \%)$ \\
Tangible Assistance & 0 & 0 & $3(42.8 \%)$ & $2(28.6 \%)$ & $2(28.6 \%)$ \\
Personal Assistance & 0 & 0 & $2(28.6 \%)$ & $3(42.8 \%)$ & $2(28.6 \%)$ \\
\hline
\end{tabular}

Table D6: Frequency of Responses to Difficulty Obtaining More Support

\begin{tabular}{|c|c|c|c|c|c|}
\hline Type of Support & Very Difficult & Difficult & Indifferent & Easy & Very Easy \\
\hline Listening & $1(14.3 \%)$ & 0 & 0 & $1(14.3 \%)$ & $5(71.4 \%)$ \\
\hline Emotional & 0 & $1(14.3 \%)$ & 0 & $3(42.8 \%)$ & $3(42.8 \%)$ \\
\hline Emotional Challenge & 0 & 0 & $1(14.3 \%)$ & $5(71.4 \%)$ & $1(14.3 \%)$ \\
\hline Reality Confirmation & $1(14.3 \%)$ & 0 & $1(14.3 \%)$ & $5(71.4 \%)$ & 0 \\
\hline Task Appreciation & 0 & 0 & $2(28.6 \%)$ & $4(57.1 \%)$ & $1(14.3 \%)$ \\
\hline Task Challenge & 0 & 0 & $1(14.3 \%)$ & $4(57.1 \%)$ & $2(28.6 \%)$ \\
\hline Tangible Assistance & 0 & $1(14.3 \%)$ & $2(28.6 \%)$ & $3(42.8 \%)$ & $1(14.3 \%)$ \\
\hline Personal Assistance & 0 & 0 & $1(14.3 \%)$ & $3(42.8 \%)$ & $3(42.8 \%)$ \\
\hline
\end{tabular}


Table D7: Frequency of responses to Having One or More Individuals Provide Support

\begin{tabular}{lccccc}
\hline Type of Support & Not Important & Little Importance & Indifferent & Important & Very Important \\
\hline Listening & 0 & 0 & $2(28.6 \%)$ & $4(57.1 \%)$ & $1(14.3 \%)$ \\
Emotional & 0 & $1(14.3 \%)$ & $2(28.6 \%)$ & $4(57.1 \%)$ & 0 \\
Emotional Challenge & $1(14.3 \%)$ & $1(14.3 \%)$ & $1(14.3 \%)$ & $4(57.1 \%)$ & 0 \\
Reality Confirmation & $1(14.3 \%)$ & 0 & $4(57.1 \%)$ & $1(14.3 \%)$ & $1(14.3 \%)$ \\
Task Appreciation & 0 & $1(14.3 \%)$ & $4(57.1 \%)$ & $2(28.6 \%)$ & 0 \\
Task Challenge & 0 & 0 & $4(57.1 \%)$ & $3(42.8 \%)$ & 0 \\
Tangible Assistance & $1(14.3 \%)$ & 0 & $3(42.8 \%)$ & $1(14.3 \%)$ & $2(28.6 \%)$ \\
Personal Assistance & 0 & $1(14.3 \%)$ & $2(28.6 \%)$ & $2(28.6 \%)$ & $2(28.6 \%)$ \\
\hline
\end{tabular}


Table D8: Satisfaction With the Quality of Support by Sport

\begin{tabular}{|c|c|c|c|c|c|c|}
\hline Type of Support & Rank & Very Dissatisfied & Dissatisfied & Indifferent & Satisfied & Very Satisfied \\
\hline \multirow{2}{*}{ Listening } & Rugby & 0 & 0 & 0 & 0 & 5 \\
\hline & Hockey & 0 & 0 & 0 & 1 & 1 \\
\hline \multirow[t]{2}{*}{ Emotional } & Rugby & 0 & 0 & 0 & 1 & 4 \\
\hline & Hockey & 0 & 0 & 0 & 1 & 1 \\
\hline \multirow[t]{2}{*}{ Emotional Challenge } & Rugby & 0 & 0 & 1 & 4 & 0 \\
\hline & Hockey & 0 & 0 & 0 & 1 & 1 \\
\hline \multirow[t]{2}{*}{ Reality Confirmation } & Rugby & 0 & 0 & 1 & 3 & 1 \\
\hline & Hockey & 0 & 0 & 1 & 1 & 0 \\
\hline \multirow[t]{2}{*}{ Task Appreciation } & Rugby & 0 & 0 & 1 & 3 & 2 \\
\hline & Hockey & 1 & 0 & 0 & 1 & 0 \\
\hline \multirow[t]{2}{*}{ Task Challenge } & Rugby & 0 & 0 & 1 & 2 & 1 \\
\hline & Hockey & 0 & 0 & 1 & 1 & 1 \\
\hline \multirow[t]{2}{*}{ Tangible Assistance } & Rugby & 0 & 0 & 2 & 2 & 1 \\
\hline & Hockey & 0 & 0 & 1 & 0 & 1 \\
\hline \multirow[t]{2}{*}{ Personal Assistance } & Rugby & 0 & 0 & 1 & 2 & 2 \\
\hline & Hockey & 0 & 0 & 1 & 1 & 0 \\
\hline
\end{tabular}


Table D9: Satisfaction With the Quality of Support by Gender

\begin{tabular}{|c|c|c|c|c|c|c|}
\hline Type of Support & Rank & Very Dissatisfied & Dissatisfied & Indifferent & Satisfied & Very Satisfied \\
\hline \multirow[t]{2}{*}{ Listening } & male & 0 & 0 & 0 & 1 & 3 \\
\hline & female & 0 & 0 & 0 & 0 & 3 \\
\hline \multirow[t]{2}{*}{ Emotional } & male & 0 & 0 & 0 & 1 & 3 \\
\hline & female & 0 & 0 & 0 & 1 & 2 \\
\hline \multirow[t]{2}{*}{ Emotional Challenge } & male & 0 & 0 & 1 & 1 & 2 \\
\hline & female & 0 & 0 & 0 & 3 & 0 \\
\hline \multirow[t]{2}{*}{ Reality Confirmation } & male & 0 & 0 & 2 & 1 & 1 \\
\hline & female & 0 & 0 & 0 & 3 & 0 \\
\hline \multirow[t]{2}{*}{ Task Appreciation } & male & 0 & 0 & 1 & 1 & 2 \\
\hline & female & 0 & 0 & 0 & 3 & 0 \\
\hline \multirow[t]{2}{*}{ Task Challenge } & male & 0 & 0 & 1 & 2 & 1 \\
\hline & female & 0 & 0 & 1 & 1 & 1 \\
\hline \multirow[t]{2}{*}{ Tangible Assistance } & male & 0 & 0 & 1 & 1 & 2 \\
\hline & female & 0 & 0 & 2 & 1 & 0 \\
\hline \multirow[t]{2}{*}{ Personal Assistance } & male & 0 & 0 & 1 & 2 & 1 \\
\hline & female & 0 & 0 & 1 & 1 & 1 \\
\hline
\end{tabular}


Table D10: Difficulty Obtaining More Support by Sport

\begin{tabular}{|c|c|c|c|c|c|c|}
\hline Type of Support & Rank & Very Difficult & Difficult & Indifferent & Easy & Very Easy \\
\hline \multirow{2}{*}{ Listening } & Rugby & 0 & 0 & 0 & 1 & 4 \\
\hline & Hockey & 1 & 0 & 0 & 0 & 1 \\
\hline \multirow[t]{2}{*}{ Emotional } & Rugby & 0 & 0 & 0 & 2 & 3 \\
\hline & Hockey & 0 & 1 & 0 & 1 & 0 \\
\hline \multirow[t]{2}{*}{ Emotional Challenge } & Rugby & 0 & 0 & 0 & 4 & 1 \\
\hline & Hockey & 1 & 0 & 0 & 1 & 0 \\
\hline \multirow[t]{2}{*}{ Reality Confirmation } & Rugby & 0 & 0 & 2 & 2 & 1 \\
\hline & Hockey & 0 & 0 & 0 & 1 & 0 \\
\hline \multirow[t]{2}{*}{ Task Appreciation } & Rugby & 0 & 0 & 0 & 4 & 1 \\
\hline & Hockey & 0 & 0 & 2 & 0 & 0 \\
\hline \multirow[t]{2}{*}{ Task Challenge } & Rugby & 0 & 0 & 0 & 3 & 2 \\
\hline & Hockey & 0 & 0 & 1 & 1 & 0 \\
\hline \multirow[t]{2}{*}{ Tangible Assistance } & Rugby & 0 & 1 & 1 & 2 & 1 \\
\hline & Hockey & 0 & 0 & 1 & 1 & 0 \\
\hline \multirow[t]{2}{*}{ Personal Assistance } & Rugby & 0 & 0 & 0 & 2 & 3 \\
\hline & Hockey & 0 & 0 & 0 & 1 & 0 \\
\hline
\end{tabular}


Table D11: Difficulty Obtaining More Support by Gender

\begin{tabular}{|c|c|c|c|c|c|c|}
\hline Type of Support & Rank & Very Difficult & Difficult & Indifferent & Easy & Very Easy \\
\hline \multirow[t]{2}{*}{ Listening } & male & 1 & 0 & 0 & 0 & 3 \\
\hline & female & 0 & 0 & 0 & 2 & 2 \\
\hline \multirow{2}{*}{ Emotional } & male & 0 & 1 & 0 & 1 & 2 \\
\hline & female & 0 & 0 & 0 & 2 & 1 \\
\hline \multirow[t]{2}{*}{ Emotional Challenge } & male & 1 & 0 & 0 & 2 & 1 \\
\hline & female & 0 & 0 & 0 & 3 & 0 \\
\hline \multirow[t]{2}{*}{ Reality Confirmation } & male & 1 & 0 & 1 & 2 & 0 \\
\hline & female & 0 & 0 & 1 & 2 & 0 \\
\hline \multirow[t]{2}{*}{ Task Appreciation } & male & 0 & 0 & 2 & 2 & 0 \\
\hline & female & 0 & 0 & 0 & 2 & 1 \\
\hline \multirow[t]{2}{*}{ Task Challenge } & male & 0 & 0 & 1 & 2 & 1 \\
\hline & female & 0 & 0 & 0 & 2 & 1 \\
\hline \multirow[t]{2}{*}{ Tangible Assistance } & male & 0 & 0 & 1 & 2 & 1 \\
\hline & female & 0 & 1 & 1 & 1 & 0 \\
\hline \multirow[t]{2}{*}{ Personal Assistance } & male & 0 & 0 & 1 & 2 & 1 \\
\hline & female & 0 & 0 & 0 & 1 & 2 \\
\hline
\end{tabular}


Table D12: Importance of Having One or More Individuals Provide Support by Sport

\begin{tabular}{|c|c|c|c|c|c|c|}
\hline Type of Support & Rank & Not Important & Somewhat Important & Indifferent & Important & Very Important \\
\hline \multirow[t]{2}{*}{ Listening } & Rugby & 0 & 0 & 1 & 3 & 1 \\
\hline & Hockey & 0 & 0 & 1 & 1 & 0 \\
\hline \multirow[t]{2}{*}{ Emotional } & Rugby & 0 & 0 & 2 & 3 & 0 \\
\hline & Hockey & 0 & 1 & 0 & 1 & 0 \\
\hline \multirow[t]{2}{*}{ Emotional Challenge } & Rugby & 1 & 0 & 1 & 3 & 0 \\
\hline & Hockey & 0 & 1 & 0 & 1 & 0 \\
\hline \multirow[t]{2}{*}{ Reality Confirmation } & Rugby & 1 & 0 & 3 & 1 & 0 \\
\hline & Hockey & 0 & 0 & 1 & 0 & 1 \\
\hline \multirow[t]{2}{*}{ Task Appreciation } & Rugby & 0 & 1 & 2 & 2 & 0 \\
\hline & Hockey & 0 & 0 & 2 & 0 & 0 \\
\hline \multirow[t]{2}{*}{ Task Challenge } & Rugby & 0 & 0 & 3 & 2 & 0 \\
\hline & Hockey & 0 & 0 & 1 & 1 & 0 \\
\hline \multirow[t]{2}{*}{ Tangible Assistance } & Rugby & 1 & 0 & 2 & 0 & 2 \\
\hline & Hockey & 0 & 0 & 1 & 1 & 0 \\
\hline \multirow[t]{2}{*}{ Personal Assistance } & Rugby & 0 & 1 & 0 & 2 & 2 \\
\hline & Hockey & 0 & 0 & 2 & 0 & 0 \\
\hline
\end{tabular}


Table D13: Importance of Having One or More Individuals Provide Support by Gender

\begin{tabular}{|c|c|c|c|c|c|c|}
\hline Type of Support & Rank & Not Important & Somewhat Important & Indifferent & Important & Very Important \\
\hline \multirow[t]{2}{*}{ Listening } & male & 0 & 0 & 2 & 1 & 1 \\
\hline & female & 0 & 0 & 0 & 3 & 0 \\
\hline \multirow[t]{2}{*}{ Emotional } & male & 0 & 1 & 2 & 1 & 0 \\
\hline & female & 0 & 0 & 0 & 3 & 0 \\
\hline \multirow[t]{2}{*}{ Emotional Challenge } & male & 1 & 1 & 1 & 1 & 0 \\
\hline & female & 0 & 0 & 0 & 3 & 0 \\
\hline \multirow[t]{2}{*}{ Reality Confirmation } & male & 1 & 0 & 2 & 0 & 1 \\
\hline & female & 0 & 0 & 2 & 1 & 0 \\
\hline \multirow[t]{2}{*}{ Task Appreciation } & male & 0 & 1 & 3 & 0 & 0 \\
\hline & female & 0 & 0 & 1 & 2 & 0 \\
\hline \multirow[t]{2}{*}{ Task Challenge } & male & 0 & 0 & 2 & 2 & 0 \\
\hline & female & 0 & 0 & 2 & 1 & 0 \\
\hline \multirow[t]{2}{*}{ Tangible Assistance } & male & 1 & 0 & 1 & 1 & 1 \\
\hline & female & 0 & 0 & 2 & 0 & 1 \\
\hline \multirow[t]{2}{*}{ Personal Assistance } & male & 0 & 0 & 2 & 1 & 1 \\
\hline & female & 0 & 1 & 0 & 1 & 1 \\
\hline
\end{tabular}


Table D14: Responses to Ranking of Those Who Provide Listening Support

\begin{tabular}{lccc}
\hline & Response $^{*}$ & Frequency & Percentage \\
\cline { 2 - 3 } Athletic trainer/physician & 1 & 5 & $71.4 \%$ \\
& 2 & 1 & $14.3 \%$ \\
Coach & 4 & 1 & $14.3 \%$ \\
& 2 & 4 & $57.1 \%$ \\
Teammates & 5 & 3 & $42.8 \%$ \\
& 2 & & \\
& 3 & 1 & $14.3 \%$ \\
Family & 4 & 4 & $57.1 \%$ \\
& 5 & 1 & $14.3 \%$ \\
& & 1 & \\
& 1 & 2 & $28.6 \%$ \\
Friends & 3 & 2 & $28.6 \%$ \\
& 4 & 4 & $14.3 \%$ \\
& 5 & 1 & $14.3 \%$ \\
& & & $14.3 \%$ \\
& 2 & 1 & $42.8 \%$ \\
& 3 & 3 & $28.6 \%$ \\
\hline
\end{tabular}

Key: ${ }^{*}$ Athletes ranked the providers from 1-5, 1=most support and 5= least support 
Table D15: Responses to Ranking of Those Who Provide Emotional Support

\begin{tabular}{|c|c|c|c|}
\hline & Response $^{*}$ & Frequency & Percentage \\
\hline \multirow[t]{5}{*}{ Athletic trainer/physician } & 1 & 2 & $28.6 \%$ \\
\hline & 2 & 1 & $14.3 \%$ \\
\hline & 3 & 2 & $28.6 \%$ \\
\hline & 4 & 1 & $14.3 \%$ \\
\hline & 5 & 1 & $14.3 \%$ \\
\hline \multirow[t]{4}{*}{ Coach } & 2 & 1 & $14.3 \%$ \\
\hline & 3 & 2 & $28.6 \%$ \\
\hline & 4 & 2 & $28.6 \%$ \\
\hline & 5 & 2 & $28.6 \%$ \\
\hline \multirow[t]{4}{*}{ Teammates } & 1 & 1 & $14.3 \%$ \\
\hline & 3 & 2 & $28.6 \%$ \\
\hline & 4 & 2 & $28.6 \%$ \\
\hline & 5 & 2 & $28.6 \%$ \\
\hline \multirow[t]{4}{*}{ Family } & 1 & 4 & $57.1 \%$ \\
\hline & 2 & 1 & $14.3 \%$ \\
\hline & 3 & 1 & $14.3 \%$ \\
\hline & 4 & 1 & $14.3 \%$ \\
\hline \multirow[t]{3}{*}{ Friends } & 2 & 4 & $57.1 \%$ \\
\hline & 4 & 1 & $14.3 \%$ \\
\hline & 5 & 2 & $28.6 \%$ \\
\hline
\end{tabular}

Key: ${ }^{*}$ Athletes ranked the providers from 1-5, 1=most support and 5= least support 
Table D16: Responses to Ranking of Those Who Provide Emotional Challenge

\begin{tabular}{lccc}
\hline & Response $^{-}$ & Frequency $^{*}$ & Percentage \\
\hline Athletic trainer/physician & 3 & 2 & $28.6 \%$ \\
& 4 & 2 & $28.6 \%$ \\
Coach & 5 & 3 & $42.8 \%$ \\
& 1 & 2 & $28.6 \%$ \\
& 2 & 3 & $42.8 \%$ \\
Teammates & 3 & 2 & $28.6 \%$ \\
& & & \\
& 1 & 1 & $14.3 \%$ \\
Family & 2 & 3 & $42.8 \%$ \\
& 3 & 1 & $14.3 \%$ \\
& 4 & 2 & $28.6 \%$ \\
Friends & 1 & & $28.6 \%$ \\
& 2 & 2 & $14.3 \%$ \\
& 4 & 1 & $28.6 \%$ \\
& 5 & 2 & $28.6 \%$ \\
& & 2 & $28.6 \%$ \\
& 1 & 2 & $14.3 \%$ \\
& 3 & 1 & $28.6 \%$ \\
\hline
\end{tabular}

Key: ${ }^{*}$ Athletes ranked the providers from 1-5, 1=most support and 5= least support 
Table D17: Responses to Ranking of Those Who Provide Reality Conformation

\begin{tabular}{|c|c|c|c|}
\hline & Response $^{*}$ & Frequency & Percentage \\
\hline \multirow[t]{4}{*}{ Athletic trainer/physician } & 1 & 1 & $14.3 \%$ \\
\hline & 2 & 2 & $28.6 \%$ \\
\hline & 4 & 2 & $28.6 \%$ \\
\hline & 5 & 2 & $28.6 \%$ \\
\hline \multirow[t]{5}{*}{ Coach } & 1 & 1 & $14.3 \%$ \\
\hline & 2 & 2 & $28.6 \%$ \\
\hline & 3 & 2 & $28.6 \%$ \\
\hline & 4 & 1 & $14.3 \%$ \\
\hline & 5 & 1 & $14.3 \%$ \\
\hline \multirow[t]{4}{*}{ Teammates } & 1 & 1 & $14.3 \%$ \\
\hline & 2 & 3 & $42.8 \%$ \\
\hline & 3 & 2 & $28.6 \%$ \\
\hline & 4 & 1 & $14.3 \%$ \\
\hline \multirow[t]{5}{*}{ Family } & 1 & 2 & $28.6 \%$ \\
\hline & 2 & 1 & $14.3 \%$ \\
\hline & 3 & 1 & $14.3 \%$ \\
\hline & 4 & 1 & $14.3 \%$ \\
\hline & 5 & 2 & $28.6 \%$ \\
\hline \multirow[t]{4}{*}{ Friends } & 1 & 2 & $28.6 \%$ \\
\hline & 2 & 1 & $14.3 \%$ \\
\hline & 4 & 2 & $28.6 \%$ \\
\hline & 5 & 2 & $28.6 \%$ \\
\hline
\end{tabular}

Key: *Athletes ranked the providers from 1-5, 1=most support and $5=$ least support 
Table D18: Responses to Ranking of Those Who Provide Task Appreciation

\begin{tabular}{|c|c|c|c|}
\hline & Response $^{*}$ & Frequency & Percentage \\
\hline \multirow[t]{4}{*}{ Athletic trainer/physician } & 1 & 1 & $14.3 \%$ \\
\hline & 2 & 2 & $28.6 \%$ \\
\hline & 4 & 2 & $28.6 \%$ \\
\hline & 5 & 2 & $28.6 \%$ \\
\hline \multirow[t]{5}{*}{ Coach } & 1 & 1 & $14.3 \%$ \\
\hline & 2 & 2 & $28.6 \%$ \\
\hline & 3 & 2 & $28.6 \%$ \\
\hline & 4 & 1 & $14.3 \%$ \\
\hline & 5 & 1 & $14.3 \%$ \\
\hline \multirow[t]{4}{*}{ Teammates } & 1 & 1 & $14.3 \%$ \\
\hline & 2 & 3 & $42.8 \%$ \\
\hline & 3 & 2 & $28.6 \%$ \\
\hline & 4 & 1 & $14.3 \%$ \\
\hline \multirow[t]{5}{*}{ Family } & 1 & 2 & $28.6 \%$ \\
\hline & 2 & 1 & $14.3 \%$ \\
\hline & 3 & 1 & $14.3 \%$ \\
\hline & 4 & 1 & $14.3 \%$ \\
\hline & 5 & 2 & $28.6 \%$ \\
\hline \multirow[t]{4}{*}{ Friends } & 1 & 2 & $28.6 \%$ \\
\hline & 2 & 1 & $14.3 \%$ \\
\hline & 4 & 2 & $28.6 \%$ \\
\hline & 5 & 2 & $28.6 \%$ \\
\hline
\end{tabular}

Key: ${ }^{*}$ Athletes ranked the providers from 1-5, 1=most support and 5= least support 
Table D19: Responses to Ranking of Those Who Provide Task Challenge

\begin{tabular}{lccc}
\hline & Response $^{*}$ & Frequency $^{-}$ & Percentage \\
\hline Athletic trainer/physician & 1 & 1 & $14.3 \%$ \\
& 2 & 1 & $14.3 \%$ \\
& 3 & 3 & $42.8 \%$ \\
Coach & 5 & 2 & $28.6 \%$ \\
& 1 & 5 & $71.4 \%$ \\
Teammates & 2 & 2 & $28.6 \%$ \\
& 2 & & \\
& 3 & 4 & $51.7 \%$ \\
Family & 4 & 2 & $14.3 \%$ \\
& 1 & 1 & $14.3 \%$ \\
& 3 & 1 & $14.3 \%$ \\
Friends & 4 & 1 & $28.6 \%$ \\
& 5 & 2 & $42.8 \%$ \\
& & 3 & $14.3 \%$ \\
& & & $51.7 \%$ \\
& & & $28.6 \%$ \\
\hline
\end{tabular}

Key: ${ }^{*}$ Athletes ranked the providers from 1-5, 1=most support and 5= least support 
Table D20: Responses to Ranking of Those Who Provide Tangible Assistance

\begin{tabular}{|c|c|c|c|}
\hline & Response $^{*}$ & Frequency & Percentage \\
\hline \multirow[t]{4}{*}{ Athletic trainer/physician } & 1 & 1 & $14.3 \%$ \\
\hline & 2 & 1 & $14.3 \%$ \\
\hline & 3 & 2 & $28.5 \%$ \\
\hline & 5 & 3 & $42.8 \%$ \\
\hline \multirow[t]{3}{*}{ Coach } & 3 & 1 & $14.3 \%$ \\
\hline & 4 & 4 & $51.7 \%$ \\
\hline & 5 & 2 & $28.6 \%$ \\
\hline \multirow[t]{4}{*}{ Teammates } & 2 & 2 & $28.6 \%$ \\
\hline & 3 & 2 & $28.6 \%$ \\
\hline & 4 & 2 & $28.6 \%$ \\
\hline & 5 & 1 & $14.3 \%$ \\
\hline \multirow[t]{2}{*}{ Family } & 1 & 6 & $85.7 \%$ \\
\hline & 3 & 1 & $14.3 \%$ \\
\hline \multirow[t]{4}{*}{ Friends } & 2 & 4 & $51.7 \%$ \\
\hline & 3 & 1 & $14.3 \%$ \\
\hline & 4 & 1 & $14.3 \%$ \\
\hline & 5 & 1 & $14.3 \%$ \\
\hline
\end{tabular}

Key: ${ }^{*}$ Athletes ranked the providers from 1-5, 1=most support and 5= least support 
Table D21: Responses to Ranking of Those Who Provide Personal Assistance

\begin{tabular}{|c|c|c|c|}
\hline & Response $^{*}$ & Frequency & Percentage \\
\hline \multirow[t]{4}{*}{ Athletic trainer/physician } & 1 & 1 & $14.3 \%$ \\
\hline & 3 & 1 & $14.3 \%$ \\
\hline & 4 & 3 & $42.8 \%$ \\
\hline & 5 & 2 & $28.6 \%$ \\
\hline \multirow[t]{3}{*}{ Coach } & 2 & 1 & $14.3 \%$ \\
\hline & 4 & 3 & $42.8 \%$ \\
\hline & 5 & 3 & $42.8 \%$ \\
\hline \multirow[t]{3}{*}{ Teammates } & 1 & 2 & $28.6 \%$ \\
\hline & 2 & 2 & $28.6 \%$ \\
\hline & 3 & 3 & $42.8 \%$ \\
\hline \multirow[t]{4}{*}{ Family } & 1 & 3 & $42.8 \%$ \\
\hline & 2 & 1 & $14.3 \%$ \\
\hline & 3 & 1 & $14.3 \%$ \\
\hline & 5 & 2 & $28.6 \%$ \\
\hline \multirow[t]{4}{*}{ Friends } & 1 & 1 & $14.3 \%$ \\
\hline & 2 & 3 & $42.8 \%$ \\
\hline & 3 & 2 & $28.6 \%$ \\
\hline & 4 & 1 & $14.3 \%$ \\
\hline
\end{tabular}

Key: ${ }^{*}$ Athletes ranked the providers from 1-5, 1=most support and 5= least support 
Table D22: Average Responses to Those Who Provided Each Type of Support

\begin{tabular}{|c|c|c|}
\hline & Provider & Mean Ranking \\
\hline \multirow[t]{5}{*}{ Listening Support } & Athletic Trainer/Physician & 1.43 \\
\hline & Coach & 3.29 \\
\hline & Teammate & 3.29 \\
\hline & Family & 3.0 \\
\hline & Friends & 3.86 \\
\hline \multirow[t]{5}{*}{ Emotional Support } & Athletic Trainer/Physician & 2.71 \\
\hline & Coach & 3.71 \\
\hline & Teammate & 3.57 \\
\hline & Family & 1.86 \\
\hline & Friends & 3.14 \\
\hline \multirow[t]{5}{*}{ Emotional Challenge } & Athletic Trainer/Physician & 4.14 \\
\hline & Coach & 2.0 \\
\hline & Teammate & 2.57 \\
\hline & Family & 3.14 \\
\hline & Friends & 3.14 \\
\hline \multirow[t]{5}{*}{ Reality Conformation } & Athletic Trainer/Physician & 3.71 \\
\hline & Coach & 1.71 \\
\hline & Teammate & 3.0 \\
\hline & Family & 3.14 \\
\hline & Friends & 3.43 \\
\hline \multirow[t]{5}{*}{ Task Appreciation } & Athletic Trainer/Physician & 3.57 \\
\hline & Coach & 2.86 \\
\hline & Teammate & 2.43 \\
\hline & Family & 3.0 \\
\hline & Friends & 3.14 \\
\hline \multirow{5}{*}{ Task Challenge } & Athletic Trainer/Physician & 3.14 \\
\hline & Coach & 1.29 \\
\hline & Teammate & 2.57 \\
\hline & Family & 3.86 \\
\hline & Friends & 4.14 \\
\hline \multirow[t]{5}{*}{ Tangible Assistance } & Athletic Trainer/Physician & 3.43 \\
\hline & Coach & 4.14 \\
\hline & Teammate & 3.29 \\
\hline & Family & 1.29 \\
\hline & Friends & 2.86 \\
\hline \multirow{5}{*}{ Personal Assistance } & Athletic Trainer/Physician & 3.14 \\
\hline & Coach & 4.14 \\
\hline & Teammate & 2.14 \\
\hline & Family & 2.57 \\
\hline & Friends & 2.43 \\
\hline
\end{tabular}


Table D23: Responses to Ranking the Types of Support

\begin{tabular}{|c|c|c|c|}
\hline & Rank Given $^{*}$ & Frequency & Percentage \\
\hline \multirow[t]{5}{*}{ Listening Support } & 1 & 1 & $14.3 \%$ \\
\hline & 2 & 2 & $28.6 \%$ \\
\hline & 3 & 2 & $28.6 \%$ \\
\hline & 6 & 1 & $14.3 \%$ \\
\hline & 8 & 1 & \\
\hline \multirow[t]{4}{*}{ Emotional Support } & 1 & 1 & $14.3 \%$ \\
\hline & 2 & 2 & $28.6 \%$ \\
\hline & 6 & 2 & $28.6 \%$ \\
\hline & 7 & 2 & $28.6 \%$ \\
\hline \multirow[t]{6}{*}{ Emotional Challenge } & 1 & 2 & $28.6 \%$ \\
\hline & 2 & 1 & $14.3 \%$ \\
\hline & 4 & 1 & $14.3 \%$ \\
\hline & 5 & 1 & $14.3 \%$ \\
\hline & 6 & 1 & $14.3 \%$ \\
\hline & 7 & 1 & $14.3 \%$ \\
\hline \multirow[t]{7}{*}{ Reality Conformation } & 1 & 1 & $14.3 \%$ \\
\hline & 2 & 1 & $14.3 \%$ \\
\hline & 3 & 1 & $14.3 \%$ \\
\hline & 4 & 1 & $14.3 \%$ \\
\hline & 5 & 1 & $14.3 \%$ \\
\hline & 6 & 1 & $14.3 \%$ \\
\hline & 8 & 1 & $14.3 \%$ \\
\hline \multirow[t]{5}{*}{ Task Appreciation } & 3 & 2 & $28.6 \%$ \\
\hline & 4 & 1 & $14.3 \%$ \\
\hline & 5 & 2 & $28.6 \%$ \\
\hline & 6 & 1 & $14.3 \%$ \\
\hline & 7 & 1 & $14.3 \%$ \\
\hline \multirow[t]{5}{*}{ Task Challenge } & 1 & 1 & $14.3 \%$ \\
\hline & 2 & 1 & $14.3 \%$ \\
\hline & 3 & 2 & $28.6 \%$ \\
\hline & 4 & 2 & $28.6 \%$ \\
\hline & 5 & 1 & $14.3 \%$ \\
\hline \multirow[t]{5}{*}{ Tangible Assistance } & 4 & 1 & $14.3 \%$ \\
\hline & 5 & 1 & $14.3 \%$ \\
\hline & 6 & 1 & $14.3 \%$ \\
\hline & 7 & 3 & $42.8 \%$ \\
\hline & 8 & 1 & $14.3 \%$ \\
\hline \multirow[t]{4}{*}{ Personal Assistance } & 1 & 1 & $14.3 \%$ \\
\hline & 4 & 1 & $14.3 \%$ \\
\hline & 5 & 1 & $14.3 \%$ \\
\hline & 8 & 4 & $57.1 \%$ \\
\hline
\end{tabular}

Key: ${ }^{*}$ Athletes ranked the types of support from 1-8, 1=most important, 8=least important 
Table D24: Averages Responses to Ranking for the Types of Social Support

Mean Rank

Listening Support

3.13

Emotional Support

3.88

Emotional Challenge

3.25

Reality Conformation

3.63

Task Appreciation

4.13

Task Challenge

2.75

Tangible Assistance

5.5

Personal Assistance

5.25

Key: Averages are based on rankings of 1-8, 1 =most important, 8=least important 
Table D25. Most Important People Providing Support Throughout Injury Process

\begin{tabular}{lcc} 
& Group 1 & Group 2 \\
Subject 1 & friends & teammates \\
Subject 2 & family & athletic trainer \\
Subject 3 & parents & coaches \\
Subject 4 & family & athletic trainer \\
Subject 5 & athletic trainer & coaches \\
Subject 6 & athletic trainer & coaches \\
Subject 7 & athletic trainer & teammates \\
\hline
\end{tabular}


Figure D1. Interview Flow Chart

\section{Raw data themes}

Hard to sit out/watch team (4)

Hard not to practice (3)

Problem walking (2)

Felt outcasted (1)

Felt frustration (3)

Problem sleeping (3)

Hard to eat (1)

Stayed involved in practice (4)

Smooth rehabilitation (4)

Needed no assistance coping (3)

Wanted more knowledge on injury (4)

Time constraints (4)
Subcategories

Injury Challenges (17)

Coping with

the injury

Rehabilitation

Process (19)
Main Categories

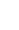


Raw data themes

Subcategories
Main Categories

Listening and

Emotional Support (39)

Athletic trainer evaluated injury (3)

Athletic trainer listened to complaints (6)

Athletic trainer showed emotional support (6)

Team listened/asked about injury (4)

Team was emotionally there (4)

Coach was un-emotional (4)

Team was understanding (4)

Family listened/asked (3)

Coach asked about progress (2)

Coach was emotionally involved (2)

Doctor listened and understood (1)

Athletic trainer set up doctor's appointment (3)

Athletic trainer set up rehab program (3)

Insurance problems (1)

No financial assistance (6)

Team/roommates gave car rides (3)

Under parents insurance (4)

Financial and

Personal Assistance (20)
Types of

Social

Support

Challenged with activities of daily living (3)

Team appreciation for attending practice (6)

Personal challenge to return to sport (5)

Challenge from rehab exercises (4)

Coach appreciation for attending practice (5)

Task Appreciation and Task Challenge (23)

Friends knew what they were going through (1) Reality

Team been injured before/shared experiences (6) 


\section{APPENDIX E}

\section{RECOMMENDATIONS FOR FUTURE RESEARCH}

1. Repeat this study using a larger number of club sport athletes (such as lacrosse and women's soccer) from the same institution.

2. Repeat this study using club sport athletes from different institutions in a geographical area.

3. Develop a more rigorous interview, by adding additional questions about receiving specific types of social support to gain more information from the club sport athletes.

4. Repeat this study by using only an interview immediately after the injury with a follow-up interview one week post injury during rehabilitation.

5. Repeat this study on perceived social support by comparing NCAA collegiate athletes with club sport athletes in similar sports.

6. Repeat this study on perceived social support using high school athletes.

7. Examine how social support can aid in proper coping after an injury by using the Brief Cope Questionnaire.

8. Repeat this study comparing club sport athletes with athletic training coverage those who do not. 


\section{ADDITIONAL REFERENCES}

25. Anshel MH. Coping styles among adolescent competitive athletes. J Soc Psychol. 1996;136(3):311-323.

26. Anshel MH, Williams LR, Williams SM. Coping style following acute stress in competitive sport. J Soc Psychol. 2000;140(6):751-73

27. DeLongis A, Folkman S, Lazarus RS. The impact of daily stress on health and mood: psychological and social resources as mediators. J Person and Soc Physcol. 1998;54(3):486-495.

28. Anshel MH, Wells B. Personal and situational variables that describe coping with acute stress in competitive sport. J Soc Psychol. 2000;140(4):434-50.

29. Ryska TA. Coping styles and response distortion on self-report inventories among high school athletes. J Psychol. 1995;127(4):409-418.

30. Victorson D, Farmer L, Burnett K, Ouellette A, Barocas J. Maladaptive coping strategies and injury-related distress following traumatic physical injury. Rehabil Psychol. 2005;50(4):408-415.

31. Ryska TA, Yin Z. Testing the buffering hypothesis: perceptions of coach support and pre-competitive anxiety among male and female high school athletes. Current Psych. 2000;18(4):381-394.

32. Smith RE, Smoll FL, Ptacek JT. Conjunctive moderator variables in vulnerability and resiliency research: life stress, social support and coping skills, and adolescent sport injuries. J Pers Soc Psychol. 1990;58(2):360-370.

33. Smith RE, Ptacek JT, Smoll FL. Sensation seeking , stress, and adolescent injuries: a test of stress-buffering, risk-taking, and coping skills hypothesis. $J$ Pers Social Psych. 1992;62(6):1016-1024.

34. Puente-Díaz R, Anshel MH. Sources of acute stress, cognitive appraisal, and coping strategies among highly skilled mexican and U.S. competitive tennis players. J Soc Psychol. 2005;145(4):429-446.

35. Quackenbush N, Crossman J. Injured athlete: a study of emotional responses. $J$ Sport Behav. 1994;17(3):178-188.

36. Udry E. Coping and social support among injured athletes following surgery. J Sport Exerc Psychol. 1997;19(1):71-90.

37. Largo-Wright E, Peterson MP, Chen WW. Perceived problem solving, stress and health among college students. Am J Health Behav. 2005;29(4):360-370. 
38. Giacobbi PR, Lynn TK, Wetherington JM, Jenkins J, Bodendorf M, Langley B. Stress and coping during the transition to university for first-year female athletes. Sport Psych. 2004;18:1-20.

39. Anderson MB, Williams JM. Athletic injury, psychosocial factors, and perceptual changes during stress. J Sport Sci. 1999;17:735-741.

40. Albinson CB, Petrie TA. Cognitive appraisals, stress, and coping: preinjury and postinjury factors influencing psychological adjustment to sport injury. J Sport Rehabil. 2003;12(4):306-322.

41. DeLongis A, Holtzman S. Coping in context: the role of stress, social support, and personality in coping. J Pers. 2005;73(6):1633-1656.

42. Price MS, Weiss MR. Relationships among coach burnout, coach behaviors, and athlete's psychological responses. Sport Psych. 2000;14:391-409.

43. Nicholls AR, Holt NL, Polman RCJ, James DWG. Stress and coping among international adolescent golfers. J Appl Sport Psychol. 2005;17(4):330-340.

44. Hanson SJ, McCullagh P, Tonymon P. The relationship of personality characteristics, life stress, and coping resources to athletic injury. J Spor Exerc Psychol. 1992;14:262-272.

45. Beets MV, Vogel R, Forlaw L, Pitetti KH, Cardinal BJ. Social support and youth physical activity: the role of provider and type. Am J Health Behav. 2006;30(3):278-289.

46. Folkman S, Lazarus RS. Coping as a mediator of emotion. J Person Soc Psychol. 1988;34(3):466-475.

47. Green SL, Weinberg RS. Relationships among athletic identity, coping skills, social support, and the psychological impact of injury in recreational participants. J Appl Sport Psychol. 2001;13(1):40-59

48. Gould D, Udry E, Bridges D. Coping with season-ending injuries. Sport Psychol. 1997;11(4):379-399.

49. Wiechman SA, Williams J. Relationship of athletic identity to injury and mood disturbance. J Sport Behav. 1997:20(2):199-210.

50. Podlog L, Eklund RC. Return to sport after serious injury: A retrospective examination of motivation and psychological outcomes. J Sport Rehabil. 2005;14(1):20-35. 
51. Reinboth M, Duda JL, Ntoumanis N. Dimensions of coaching behavior, need, satisfaction, and the psychological and physical welfare of young athletes. Motivat Emot. 2004;28(3):297-313.

52. Gayman AM, Crossman J. A qualitative analysis of how the timing of the onset of sports injuries influences athlete reactions. J Sport Behav. 2003;26(3):255272.

53. Dunn JL. Helping athletes cope with grief. Coach Athc Dir. 1997;66(10):12-14.

54. Barone JE, Ivy ME. Resident work hours: the five stages of grief. Academ Med. 2004;79(5):379-380.

55. Davis GF. Loss and the duration of grief. J Amer Med Assoc. 2001;285(9):11521155.

56. Mason S, Turpin G, Woods D, Wardrope J, Rowlands A. Risk factors for psychological distress following injury. Brit J Clinc Psychol. 2006;45:217-230.

57. Frischenschlager O, Pucher I. Psychological management of pain. Disabil Rehab. 2002;24(8):416-422.

58. Udry E. Staying connected: optimizing social support for injured athletes. Athl Ther Today. 2002;7(3):42-43.

59. Leifer FM. Perverse effects of social support: publics and performance in major league sports. Soc Forces. 1995;74(1):81-121.

60. Winelfield HR. Social support and psychological well-being in young adults: the multi-dimensional support scale. J Person Assess. 1992;58(1):198-210.

61. Hardy CJ, Richman JM, Rosenfeld LB. The role of social support in the life stress/injury relationship. Sport Psychol. 1991;5(2):128-139.

62. Rees T, Smith B, Sparkes AC. The influence of social support on the lived experiences of spinal cord injured sportsmen. Sport Psychol. 2003;17(2):135157. 